\title{
Article \\ A Persona-Based Approach for Identifying Accessibility Issues in Elderly and Disabled Users' Interaction with Home Appliances
}

\author{
Joong Hee Lee ${ }^{1,+} \mathbb{1}$, Yong Min Kim ${ }^{1,+}$, Ilsun Rhiu ${ }^{2, * \mathbb{C}}$ and Myung Hwan Yun ${ }^{1, *(\mathbb{D})}$ \\ 1 Department of Industrial Engineering \& Institute for Industrial System Innovation, Seoul National University, \\ Seoul 08826, Korea; jetishie@snu.ac.kr (J.H.L.); fides.ymkim@gmail.com (Y.M.K.) \\ 2 Division of Future Convergence (HCI Science Major), Dongduk Women's University, Seoul 02748, Korea \\ * Correspondence: isrhiu@dongduk.ac.kr (I.R.); mhy@snu.ac.kr (M.H.Y.); \\ Tel.: +82-2-940-4786 (I.R.); +82-2-880-1403 (M.H.Y.) \\ + These authors contributed equally to this work.
}

Citation: Lee, J.H.; Kim, Y.M.; Rhiu, I.; Yun, M.H. A Persona-Based

Approach for Identifying

Accessibility Issues in Elderly and Disabled Users' Interaction with Home Appliances. Appl. Sci. 2021, 11, 368. https://doi.org/10.3390/ app11010368

Received: 1 December 2020 Accepted: 29 December 2020 Published: 1 January 2021

Publisher's Note: MDPI stays neutral with regard to jurisdictional clai$\mathrm{ms}$ in published maps and institutional affiliations.

Copyright: (C) 2021 by the authors. Licensee MDPI, Basel, Switzerland. This article is an open access article distributed under the terms and conditions of the Creative Commons Attribution (CC BY) license (https:// creativecommons.org/licenses/by/ $4.0 /)$.

\begin{abstract}
Disabled and elderly populations may not fully appreciate the benefits of advanced technologies and every-day products due to accessibility issues. However, the diverse characteristics of disabled and elderly users make conducting user research a challenging task for stakeholders who oversee the needs of developing accessible products. They need a tool providing rich information to empathize with the disabled and elderly users, instead of standards and documents without detailed explanation of real-world applications. Therefore, this study aims to identify accessibility issues based on the interview and observation data from 52 people with different disabilities and ages. We developed eight personas representing four different user groups under the context of home appliance usage: visually impaired, hearing impaired, spinal-cord impaired, and elderly. Each persona takes a role as a tool to understand the target users and has a persona card representing their task barriers, frustrations, needs, and quotations along with a cartoonized character. In this study, we address two common accessibility issues and two persona-specific issues within each user group. The issues are presented in stakeholder's language personas to help them comprehend and empathize with their users.
\end{abstract}

Keywords: personas; user experience; disability; elderlies; home appliances; context-of-use

\section{Introduction}

\subsection{Home Appliances and Accessibility}

The advent of innovative technologies with modern features and services that make life more convenient and comfortable exists is presently taking place. The latest technologies, including home appliances, deliver benefits to our lives; however, due to the lack of accessibility support from the manufacturers and designers, a considerable number of people in need of accessibility support have been ignored. Such technologies may lead to more difficulties for some users when utilizing them to achieve their desired goals than outdated products would have. In particular, it is challenging for disabled users and elderlies who have diminished function in vision, hearing, or even mobility to fully appreciate the newly released top-notch technologies due to their issues with impaired modality and mobility or even lack of experience.

The World Health Organization [1] reported that the number of people living with one or more disabilities is more than one billion-nearly $15 \%$ of the world population-and almost 200 million experience considerable difficulties in functioning. The number of the disabled population may grow larger in number because most disabilities are acquired during the lifetime of an individual rather than being congenital [2,3]. It is sensible to reckon that these users will confront unreasonable endeavors of both cognitive and physical 
manner, along with consequent safety issues if there is no accessibility support given for them when using daily appliances. It is important to assure that such users do not feel that they are dependent or need help in their everyday life issues [4,5] when using a product.

Presently, stakeholders, including manufacturers, recognize that there is a significant population with accessibility issues using their products. Moreover, it is a major social responsibility of manufacturers to ensure a product is accessible to diverse users [6], especially for the manufacturers of home appliances that fulfill the core needs of human life. According to the report of the Ministry of Trade, Industry, and Energy in South Korea in 2014 [7], accessibility issues are prevalent with home appliances, such as washing machines, microwaves, and refrigerators for people with visual impairment, hearing impairment, and upper and lower limb impairments. In this study, we chose the washing machines, microwaves, ovens, and cooktops as target appliances. These all require a user to perform a similar task sequence to operate; a user loads an object in or on the appliance, delivers control commands, monitors the operational status, fixes an error at its occurrence, and unloads the object from the appliance. Moreover, the structures or mechanisms of the major home appliances do not differ significantly by countries from those in Korea, and the users with the same type of disability will experience similar problems outside of Korea, accordingly.

\subsection{Guidelines and Standards for Accessibility}

In response, there are various standards and documents published to deliver guidelines for accessible products, albeit with three major limitations. First, the coverage of target users is insufficient in some documents. The United States government has published the Americans with Disabilities Act (hereafter, ADA), including ADA standards [8] for accessible design with recommended numbers and measures so that manufacturers and designers can utilize them as design reference. Although the ADA standard provides design guidelines for various home appliances such as refrigerators, ovens, cooktops, washers, and dryers, its main target user is the wheelchaired population, disregarding the remaining disability groups and elderlies. On the other hand, IEC 63008 [9] provides design guidelines for operable parts such as doors, lids, drawers, and controls for users with various types of impairments, whereas the ADA focuses on the home appliance as a whole product for the specific disabled population. IEC 63008 certainly considered multiple user groups with various impairments and stated that such impairments become more severe as a user ages; however, elderly users are not included as a target user that may encounter different contexts of use. Most ISO documents related to the accessibility, other than ISO 22411 [10] and ISO 9241-20 [11], also omitted elderly users.

Another limitation of such documents is the target domains of the application. Despite the wide coverage of disability types, many ISO documents such as ISO 9241-20, ISO TR 29138-1, and ISO TS 16071 [11-13] mostly focused on the context of software or web accessibility issues. It can be challenging for manufacturers to directly apply the given user needs from the standards into their physical product development. This is because the user behaviors for Graphical User Interfaces (GUIs), such as web or software activities, which are mostly cognitive with minimal physical tasks, can differ from the user interactions for a product with Physical User Interfaces (PUIs). In terms of physical designs, the ADA standard may fall into this category since it provides some physical design guidelines for home appliances as stated earlier. However, the ADA standard preferably provides guidelines mostly for environmental designs rather than for product designs since it is especially targeted for the mobility of wheelchair users; the design guidelines for home appliances are minimal and obscure. IEC 63008 is also a physical design guideline; however, it is insufficient for a designer or manufacturer who designs a whole product since it delivers the guidelines only for the operable parts.

Finally, the aforementioned standards and documents are not written in a language easily comprehensible by designers and manufacturers. The designers and manufacturers who are new to the concept of accessibility may not fully utilize or comprehend the contents 
of these standards due to the lack of detailed explanation on the context of use [14]. The ADA standard provides design guidelines with recommended numbers and measures so that manufacturers and designers can utilize them as design reference. However, ADA's guidelines are obscure or rather minimal as they do not explain how they derived such numeric values. There should be descriptions of a target user's behavior or possible use case scenarios for readers to understand the context of use and implement the values in their designs.

Such documents will help manufacturers to logically understand the fact that many potential users encounter such accessibility issues in their ordinary lives; however, the specific needs and frustrations of disabled users when using inaccessible products will only remain unknown, vague, and without empathy. The lack of empathy can breed many misconceptions of disabled users, created by misinterpretation of disabled people's experiences and knowledge $[15,16]$, since the stakeholders themselves have never experienced what it is like to be a disabled user [17]. This does not mean they are not applicable at all, because these documents can be useful for the accessibility experts to undergo accessibility assessment on various products and to design their control compartments with recommended design specification with numeric references. However, one must remember that not all readers have pre-built empathy and expertise to directly implement the given numbers. In short, such already-available information is not suitably presented in terms of the stakeholders' language $[15,18]$. Therefore, it is an essential prerequisite to investigate and empathize with the users by leveraging appropriate user studies to build empathy and expertise before reading the aforementioned guidelines.

\subsection{User Profiling and Modeling}

A suitably selected and conducted user research method can provide abundant meaningful insights depending on the focus of the study [19]. The user-centered approach allows designers and manufacturers to successfully construct user profiles or user models, which is essential to understand the vulnerable user population like the disabled and elderly users. However, there is a barrier for stakeholders when they conduct user research for the users in need of accessibility support. This barrier of inaccessibility is not one-directional but mutual; it is also inaccessible for the stakeholders to hear from their target users about their experience; ironically, it is similar to how it was not accessible for users to appreciate the designs from the stakeholders.

There are several methods of collecting user profiling data along with important factors-inaccessibility problems - to consider in advance, especially for the vulnerable yet inaccessible population. For example, when conducting a survey, the same questionnaires must be in various formats to meet the capability of users. It must be screen-readercompatible for visually impaired users, neither verbose nor too complex for sign language users, less burdensome to answer for physically disabled users, and given in both manual and online formats for elderly users with lower ICT (Information and Communications Technology) ability [20-22]. Other user research methods also have the same barrier issue. Interviews require a dedicated moderator to create adequate rapport to encourage participants to share their true experience with accessibility issues in detail [17]. It also requires a skillful sign language translator for interviewing deaf participants in addition to an experienced moderator [23,24]. Day Reconstruction Method (DRM) reduces participants' burden of recoding episodes by imposing a chronological process only in a daily manner. However, it still requires highly systematic participation and engagement of disabled users to record their specific user experiences $[25,26]$. Most critically, it is challenging to recruit disabled and elderly users and to manage an interview or observation session. While taking into account all the considerable factors above, this study adopted the Focus Group Interview (FGI) and on-site observation methods.

Furthermore, we developed personas for each group by the collected data from FGI and observation to highlight the user issues. When it is inaccessible for a manufacturer to obtain actual users' needs and their behaviors toward a product, personas can be a great 
substitute for the target users because personas help stakeholders to empathize with their user with more profound understanding $[15,18,27]$ and are especially useful when it is challenging to recruit the target users [28]. A persona is a realistic but fictitious individual user that represents the target user's characteristics, needs, behaviors, objectives, and expectations [29,30]. Personas based on user research can help manufacturers recognize and empathize with the needs in accessibility for people with disabilities since the personas define not only the users and user characteristics but also the problems they experience throughout given scenarios. The personas are presented in the form of a designer's language rather than cold, unempathizeable tables and charts.

Recently, there have been new techniques with a quantitative approach adopted for persona development, such as survey statistics and text-mining [31,32]. However, most of the persona studies still use a qualitative approach. Studies with a qualitative approach are highly focused on the persona's use case scenarios and probable frustrations and needs while lacking an explanation of how personas are made. Furthermore, the data collected from the disabled and elderly users in this study are best suited to the qualitative approach as well. Thus, this study borrowed one of the traditional methods to create personas from Pruitt and Adlin [33]. Previous studies created personas for disabled users $[18,20,34-37]$ and also approved the effectiveness of personas when applied in studies on disabled people. In particular, Schulz and Fuglerud [35] suggested targeting four main groups of disabilities when developing disability personas: people with vision, hearing, movement, and cognitive impairments. They also recommended considering the elderly as well, if possible, since the elderly populations suffer from a combination of several milder versions of impairments from these four groups. Therefore, by taking the suggestions, this study developed personas of disabled people under the context of home appliance usage to investigate their user needs and frustration, presented in forms of stakeholder's (manufacturers and designers) language so that they can empathize with the disabled users.

Overall, this study aims to extract accessibility issues of disabled and elderly users within the context of home appliance usage via the persona approach. This study created personas representing target user groups from FGIs and observations. Each persona addresses accessibility issues and possible solutions.

\section{Methods}

This study developed personas for four groups of disabled and elderly users based on the procedure described in Figure 1. The basis of personas comprises qualitatively selected insights from the focus group interviews and observation. We collected the user experience data from both Focus Group Interview and observation and qualitatively analyzed them. Finally, we created personas representing each user group, which indicate their user characteristics, behaviors, task barriers and goals, needs and frustration, and accessibility issues. 


\section{UX Data Collection}

UX Data Analysis

\section{Accessibility Issue Discovery}

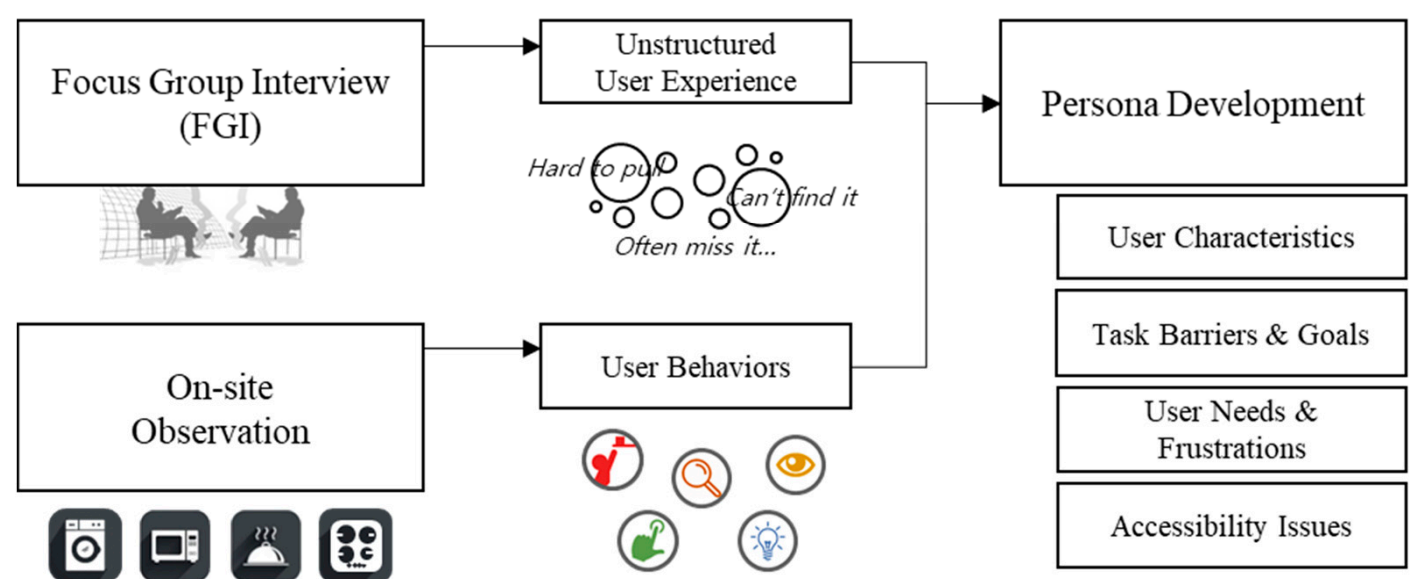

Figure 1. Overview of study procedure to investigate the accessibility issues.

\subsection{User Experience Data Collection}

A total of 52 people with different disabilities and age (14 visually impaired, 13 hearing impaired, 9 spinal-cord impaired, and 16 elderly) participated. All participants were invited to an interview site with pre-installed home appliances. In advance of the site visits, visually impaired participants and elderly groups were verbally instructed through phone calls, along with documented instructions. Special transportation was prepared for visually impaired and spinal-cord-impaired people. We also hired a sign language translator for the hearing-impaired group as well.

All participants completed a set of basic survey questionnaires on their daily behaviors with the target appliances and frustration and needs in advance of the interview and observation. The questionnaires asked demographic characteristics such as gender, age, family member, currently used assistive devices, acquisition of disability, dependent sensation, the activeness of household work (7-point-Likert scale), and perceived ICT ability (7-point-Likert scale).

Focus Group Interviews for each target group were conducted so that the users with similar challenges could share their various experiences and either agree or disagree on the accessibility issues that each individual experienced. Furthermore, the participants could try out pre-installed home appliances during the interview to recall specific needs and frustrations, which they could have forgotten to provide for a survey. All participants interacted with the washing machine, microwave, oven, and gas and electric stoves and freely expressed both poorly designed and well-designed aspects of pre-installed appliances in terms of their disability and age characteristics. Consequently, all of their responses were recorded with the corresponding appliance. Their behaviors of using the appliances were observed and documented.

Each interview session asked the participants to share their experience and opinions of the inconvenience of using the target home appliances based on five different task phases for the chronological sequence of product usages: pre-usage (preparation or set-up), usage (input control), mid-usage (monitoring in the midst of operation process), post-usage (wrap-up), and maintenance phase. The definition and example of each phase are given in Table 1. 
Table 1. Definitions and examples of timely phase when using home appliances.

\begin{tabular}{|c|c|c|}
\hline Timely Phase & Definition & Example Tasks \\
\hline Pre-Usage (Preparation) & $\begin{array}{l}\text { A preparation-related phase } \\
\text { for a user to load an object } \\
\text { in/on an appliance }\end{array}$ & $\begin{array}{l}\text { Opening/closing a door, } \\
\text { Carrying, Placing an object }\end{array}$ \\
\hline Usage (Control) & $\begin{array}{l}\text { A control-related phase for a } \\
\text { user to give an operational } \\
\text { command to an appliance }\end{array}$ & $\begin{array}{l}\text { Searching, Selecting, } \\
\text { Feedback-receiving, } \\
\text { Operating }\end{array}$ \\
\hline Mid-Usage (Monitoring) & $\begin{array}{c}\text { A monitoring phase for a user } \\
\text { to check an appliance's } \\
\text { operational or error status }\end{array}$ & $\begin{array}{c}\text { Feedback-receiving, Planning, } \\
\text { Status-checking }\end{array}$ \\
\hline Post-Usage (Wrap-up) & $\begin{array}{c}\text { A wrap-up phase for a user to } \\
\text { unload an object from an } \\
\text { appliance }\end{array}$ & $\begin{array}{c}\text { Same as that of pre-usage but } \\
\text { in reverse order }\end{array}$ \\
\hline Maintenance/Installment & $\begin{array}{c}\text { A phase where an appliance is } \\
\text { not under operation until the } \\
\text { next cycle }\end{array}$ & $\begin{array}{l}\text { Cleaning, Status-checking, } \\
\text { Assembling/disassembling }\end{array}$ \\
\hline
\end{tabular}

\subsection{Data Analysis for Personas}

Some existing studies have created personas for disabled people [35,38-41]; however, there is no detailed explanation of how the personas were created, though they are rich in personal information about their personas. This study burrowed the persona creation method developed by Pruitt and Adlin [33], as shown in Figure 2. They suggested identifying the "ad hoc" persona in the beginning. The development of ad hoc personas helps articulate the initial assumption toward the target users. It also helps set up the starting point of persona creation. This study chose the visually impaired, hearing-impaired, spinalcord-impaired, and elderly users as the target users in accordance with the suggestions made by Schulz and Fuglerud for creating personas for disabilities [35], which became the ad hoc personas for this study, the first step of persona creation.

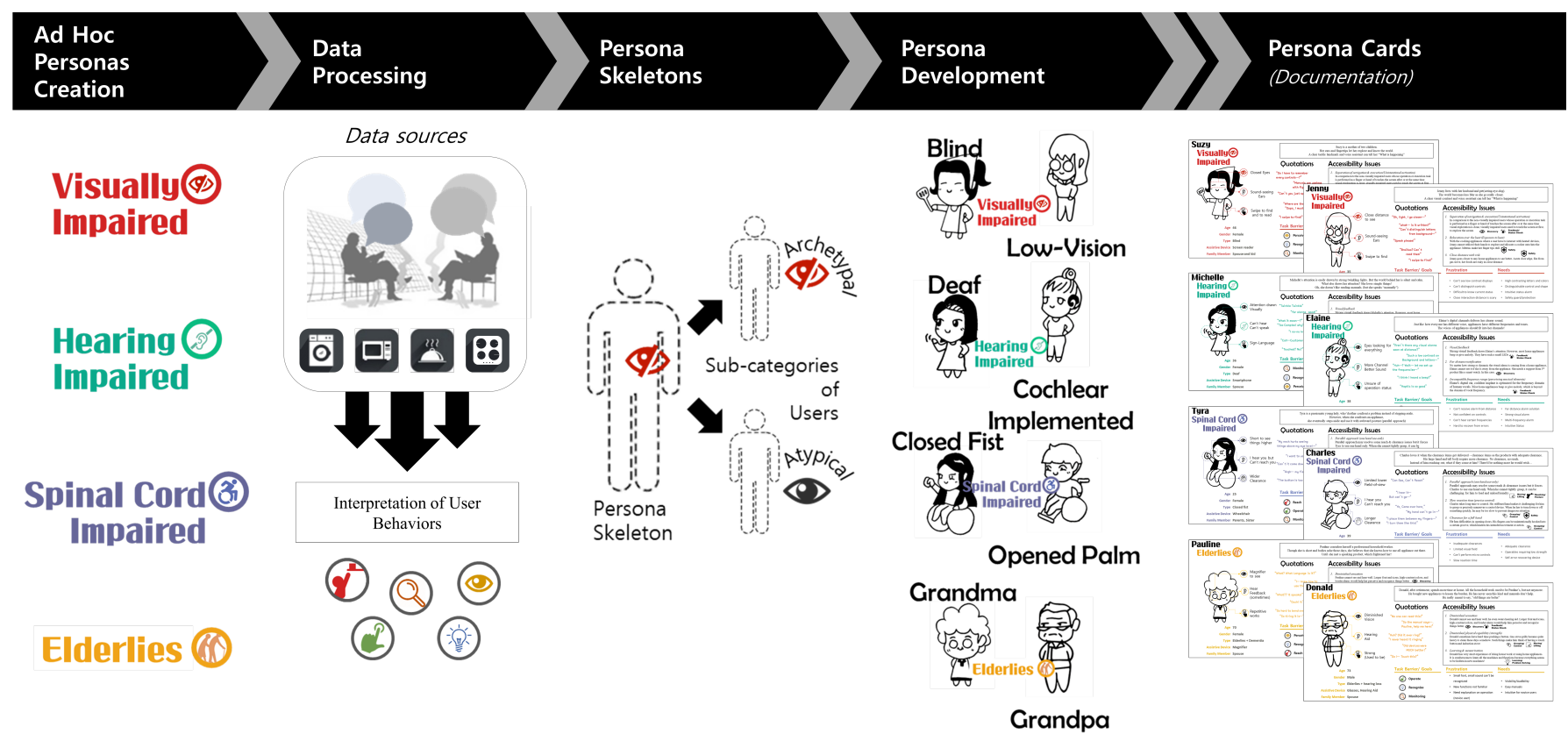

Figure 2. The flow of persona creation borrowed from Pruitt and Adlin [33].

Consequently, for data processing, verbally recorded audio from both FGI and observation sessions were manually transcribed and translated by four ergonomic professionals. For the investigation of the accessibility issues under the context of home appliance usage, 
each meaningful sentence representing their user experience and behavior was scrutinized and sorted based on the characteristics of target user groups, relevant product and compartment, usage phase, and task characteristics. In terms of task characteristics, we borrowed the five accessibility operational tasks (perceive, recognize, monitor, reach, operate) from IEC 63008 [9] to sort the relevant tasks. The five tasks consist of three informative tasks (perceive, recognize, and monitor) and two physical tasks (reach and operate). Table 2 describes the extended definition of user tasks borrowed and edited from the accessibility operational tasks of IEC 63008 used in this study. We counted each issue regarding its task characteristics and context to understand the representative accessibility issues within the user groups.

Table 2. Definition of accessibility operational tasks.

\begin{tabular}{|c|c|c|}
\hline $\begin{array}{c}\text { Accessibility Operational } \\
\text { Tasks }\end{array}$ & Definition (IEC 63008 [9]) & $\begin{array}{l}\text { The Extended Definition } \\
\text { Used in This Study }\end{array}$ \\
\hline Perceive & $\begin{array}{l}\text { To find the product and its } \\
\text { parts required to perform the } \\
\text { task }\end{array}$ & $\begin{array}{l}\text { The searching task for } \\
\text { information and product } \\
\text { compartment of interest via } \\
\text { sensory channels. }\end{array}$ \\
\hline Recognize & $\begin{array}{l}\text { To identify/understand the } \\
\text { parts required to perform the } \\
\text { task }\end{array}$ & $\begin{array}{l}\text { Identification/comprehension } \\
\text { of perceived information or } \\
\text { product part, including } \\
\text { prediction or planning for } \\
\text { consequent tasks }\end{array}$ \\
\hline Monitor & $\begin{array}{l}\text { To receive feedback on the } \\
\text { operation }\end{array}$ & $\begin{array}{c}\text { Reception of feedbacks and } \\
\text { inspection of the current } \\
\text { status }\end{array}$ \\
\hline Reach & $\begin{array}{l}\text { Physical access to the parts } \\
\text { required to perform the task }\end{array}$ & $\begin{array}{l}\text { Partial or whole-body access } \\
\text { (reach and clearance) to } \\
\text { product compartments of } \\
\text { interest, including the } \\
\text { positioning and grasping }\end{array}$ \\
\hline Operate & To perform the task & $\begin{array}{l}\text { Any physical movements } \\
\text { related to the achievement of } \\
\text { main goals, including pulling, } \\
\text { pushing, pressing, etc. }\end{array}$ \\
\hline
\end{tabular}

There was a need to split the ad hoc persona in the persona skeleton development procedure, where it verifies the categories of users and identifies subcategories of users. We considered the following criteria when segregating the user groups: (1) differences in the level of utilization of body parts with a disability; (2) physical differences such as height, strength, or shape; and (3) differences in experience and attitude regarding the use of home appliances. Consequently, we considered whether these differences potentially lead to different and distinct accessibility issues (frustrations and needs) and solution approaches. Of course, the number of personas can diverge, and there is no magic number of personas [33]. However, personas are not for describing every single user, but for the representative user groups. Moreover, the number of personas should be manageable. Therefore, based on the data we collected, we aimed to develop each archetypal and atypical persona within a user group.

\subsection{Persona Creation for Identifying Accessibility Issues}

Consequently, consistent organized data and insights were leveraged to create personas conveying the frustration and needs of each user group. Each persona visualized their accessibility issues in a form of a persona card for easier comprehension and empathy. This procedure belongs to the later phase of the persona creation flow in Figure 2.

As shown in Figure 3, we developed a persona card template, which consists of the collected demographics and task characteristics in terms of task barriers and goals, user 
frustrations and needs, representative quotations, and cartoon characters representing the virtual users of each disabled or elderly group.

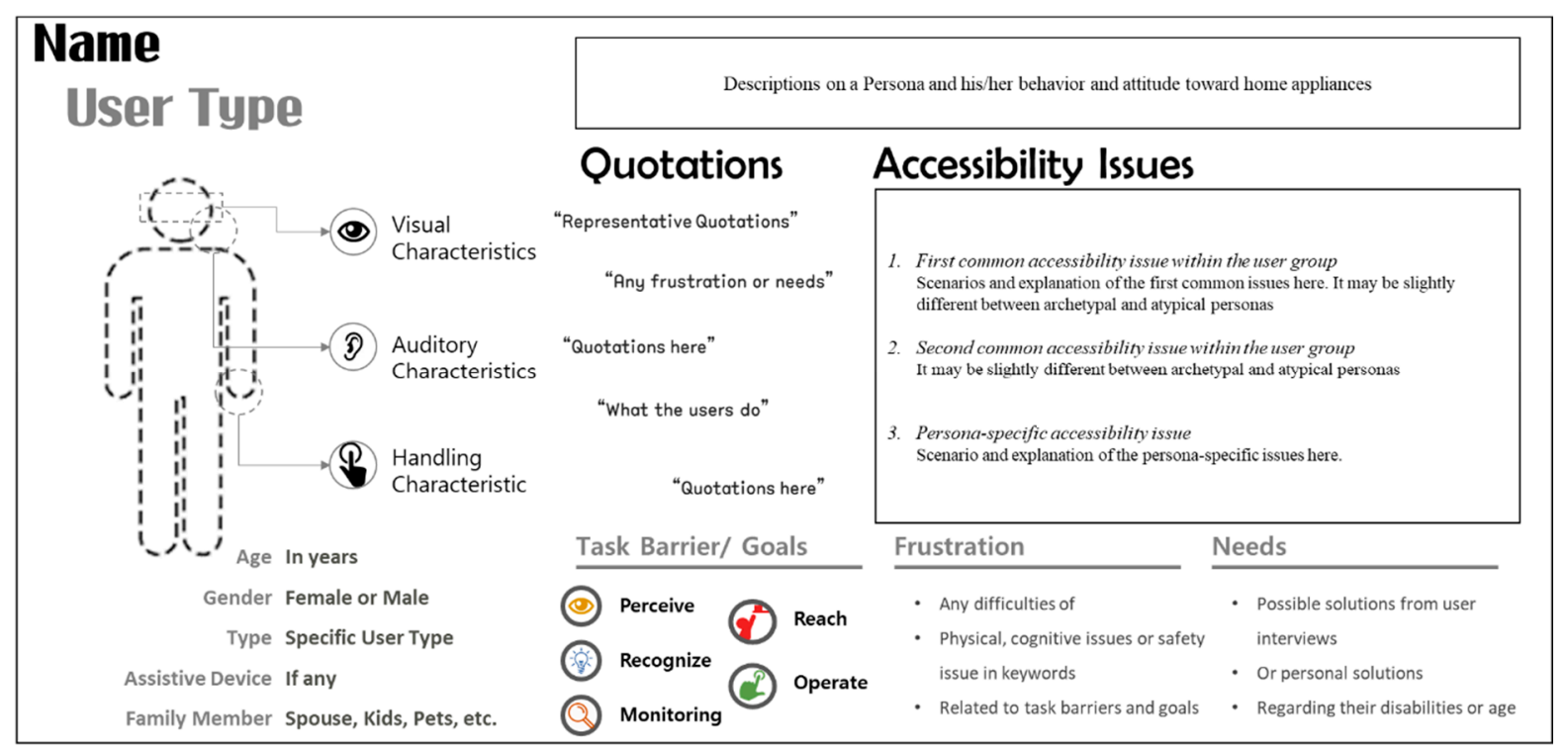

Figure 3. Persona card template.

The cartoon characters represent the physical characteristics of disabled users and elderlies along with assistive devices, if any. The task barriers and goals specify the context, whereas the quotations along with the frustration and needs of a specific persona describe the actual accessibility issues of using home appliances under the context. Therefore, we intended that one can grasp the overall accessibility issues by personas since each persona reflects the majority of demographics and accessibility issues to be a representative persona. It is also worth noting that based on our research, we developed additional personas representing some specific issues and characteristics, though they may not be the majority of collected data within their user group since the difference in user characteristics was the main criterion for the within-group persona segregation. Personas for the users with informational disabilities (visual or hearing impairment) diverged based on the level of dependency in their disabled sensations, that is, whether they can still utilize their disabled sensory channel to retrieve information. For spinal-cord-impaired personas, who represent physical disability, the differences in hand shape and gender were the key distinctive features to specify their personas, which indicate the different height and reach/clearance issues. Finally, gender was the main criterion to differentiate two elderly personas who have different anthropometric characteristics and their experience in household works.

Finally, each persona was given three accessibility issues: two as common issues within its user group, and the other as persona-specific. For the common issues, the number of issues was counted, and the issue with a high number was chosen as the common issue. On the other hand, the persona-specific issue is assigned to each persona with similar criteria to that of persona segregation because this issue does not overlap with the issues for the other personas. The persona-specific issue must be led by (1) the differences in the level of utilization of disabled/diminished parts; (2) physical differences such as height, strength, or shape; and (3) differences in experience and attitude regarding the use of home appliances. When prioritizing the issues for both common and persona-specific, an issue arises related to prevention of autonomous usage, safety issue, and its potential to induce different and distinct design solutions. The issues in persona cards are written in a narrative or scenario-like form. 


\section{Results}

\subsection{Persona Behaviors and Characteristics}

The demographics of the participants are shown in Table 3. There were relatively more female users among the user groups, other than the spinal-cord-injured users. The average ages of visually impaired, hearing impaired, spinal-cord-impaired, and elderly users were 41.6, 38.1, 33.6, and 73.1 years old, respectively. Approximately $77 \%$ of participants had acquired disabilities, while the participants with a congenital disability were $23 \%$. In addition, two of the elderlies had acquired disabilities, namely hearing loss and brain lesion. The activeness of household work was over 5 out of 7 points for all user groups, other than the spinal-cord-impaired user group. The perceived ICT-ability of each user group was 5, 5.69, 5, and 3.93 for visually impaired, hearing impaired, spinal-cord-impaired, and elderly users, respectively. In terms of an assistive device, visually impaired users use a screen-reader and magnifier the most, while hearing-impaired users use hearing aids and cochlear implant devices. Spinal-cord impaired users were all equipped with wheelchairs, and elderly users used glasses and hearing aids.

Table 3. Demographics of participants.

\begin{tabular}{|c|c|c|c|c|c|}
\hline \multicolumn{2}{|c|}{ Demographics } & $\begin{array}{l}\text { Visually } \\
\text { Impaired } \\
(n=14)\end{array}$ & $\begin{array}{l}\text { Hearing } \\
\text { Impaired } \\
(n=13)\end{array}$ & $\begin{array}{c}\text { Spinal-Cord } \\
\text { Impaired } \\
(n=9)\end{array}$ & $\begin{array}{l}\text { Elderly } \\
(n=16)\end{array}$ \\
\hline \multirow{3}{*}{ Age } & Average & 41.6 & 38.1 & 33.6 & 73.1 \\
\hline & Min & 24 & 25 & 20 & 67 \\
\hline & Max & 65 & 64 & 45 & 81 \\
\hline \multirow{2}{*}{ Gender } & Female & $9(64 \%)$ & $8(62 \%)$ & $3(33 \%)$ & $11(69 \%)$ \\
\hline & Male & $5(36 \%)$ & $5(38 \%)$ & $6(67 \%)$ & $5(31 \%)$ \\
\hline \multirow{2}{*}{ Disability } & Congenital & $5(36 \%)$ & $7(54 \%)$ & $0(0 \%)$ & $14(0 \%)$ \\
\hline & Acquired & $9(64 \%)$ & $6(46 \%)$ & $9(100 \%)$ & $2(12.50 \%) *$ \\
\hline \multirow{3}{*}{$\begin{array}{l}\text { Dependent } \\
\text { sensations }\end{array}$} & Visual & $8(57 \%)$ & $10(77 \%)$ & $9(100 \%)$ & - \\
\hline & Auditory & $11(79 \%)$ & $5(38 \%)$ & $6(67 \%)$ & - \\
\hline & Tactile & $11(79 \%)$ & $3(23 \%)$ & $4(44 \%)$ & - \\
\hline \multicolumn{2}{|c|}{ Household work activeness } & 5.00 & 5.63 & 3.33 & 5.50 \\
\hline \multicolumn{2}{|c|}{ Perceived-ICT-ability } & 5 & 5.69 & 5 & 3.93 \\
\hline \multicolumn{2}{|c|}{ Assistive Devices } & $\begin{array}{c}\text { Screen reader, } \\
\text { Magnifier }\end{array}$ & $\begin{array}{l}\text { Hearing aids, } \\
\text { Cochlear } \\
\text { implant }\end{array}$ & Wheelchair & $\begin{array}{c}\text { Glasses, } \\
\text { Hearing aids }\end{array}$ \\
\hline
\end{tabular}

* two elderlies acquired hearing loss and brain lesion.

The number of accessibility issues found during the interview and observation sessions regarding the user groups is as shown in Table 4 . All the accessibility issues were organized based on the five accessibility tasks and chronological product usage phases. The total number of issues from each user group was $89,55,92$, and 59 for visually impaired, hearing impaired, spinal-cord impaired, and elderly users, respectively. For the visually impaired users, accessibility issues with monitoring tasks appeared the most, followed by recognize, perceive, operate, and reach tasks (see Table 4). For example, visually impaired users have a hard time monitoring the current position or status of home appliances and recognizing what they touched and were afraid to reach out or touch a surface with heat. The hearing-impaired users also showed a similar trend of monitoring tasks being the most frequent, followed by recognize, operate, reach, and perceive tasks (see Table 4). On the other hand, there were accessibility issues with reach tasks the most with spinal-cord impaired users, followed by operate, monitor, recognize, and perceive tasks (see Table 4). Finally, for the elderly users, the accessibility issues were comparably balanced among the 
four tasks except for the perceive task, while the operate task was the most frequent issue (see Table 4). Most of the comments from participants dealt with inaccessible issues.

Table 4. Accessibility issues counted for visually impaired/hearing impaired/spinal-cord impaired/elderly users.

\begin{tabular}{|c|c|c|c|c|c|c|}
\hline \multirow{2}{*}{ Timely Context } & \multicolumn{5}{|c|}{ IEC 63008 Accessibility Test Task } & \multirow{2}{*}{ Counts } \\
\hline & Perceive & Recognize & Monitor & Reach & Operate & \\
\hline Pre-Usage & 4 & 3 & 4 & & 3 & 14 \\
\hline Usage & 9 & 17 & 21 & & 5 & 52 \\
\hline Mid-Usage & 1 & 2 & 8 & & & 11 \\
\hline Post-Usage & 1 & & 4 & 1 & 1 & 7 \\
\hline Maintenance & & 2 & 3 & 1 & & 5 \\
\hline Counts & 15 & 24 & 40 & 1 & 9 & 89 \\
\hline \multirow{2}{*}{ Timely Context } & \multicolumn{5}{|c|}{ IEC 63008 Accessibility Test Task } & \multirow{2}{*}{ Counts } \\
\hline & Perceive & Recognize & Monitor & Reach & Operate & \\
\hline Pre-Usage & & 1 & 1 & 1 & 2 & 5 \\
\hline Usage & 3 & 11 & 8 & 1 & & 23 \\
\hline Mid-Usage & & 1 & 11 & & & 12 \\
\hline Post-Usage & & & 2 & 4 & 2 & 8 \\
\hline Maintenance & 1 & & 3 & & 3 & 7 \\
\hline Counts & 4 & 13 & 25 & 6 & 7 & 55 \\
\hline \multirow{2}{*}{ Timely Context } & \multicolumn{5}{|c|}{ IEC 63008 Accessibility Test Task } & \multirow{2}{*}{ Counts } \\
\hline & Perceive & Recognize & Monitor & Reach & Operate & \\
\hline Pre-Usage & 2 & 3 & & 23 & 5 & 33 \\
\hline Usage & 2 & 2 & 7 & 9 & 12 & 32 \\
\hline Mid-Usage & 1 & & & & 2 & 3 \\
\hline Post-Usage & & & & 15 & 2 & 17 \\
\hline Maintenance & & & 1 & 3 & 3 & 7 \\
\hline Counts & 5 & 5 & 8 & 50 & 24 & 92 \\
\hline \multirow{2}{*}{ Timely Context } & \multicolumn{5}{|c|}{ IEC 63008 Accessibility Test Task } & \multirow{2}{*}{ Counts } \\
\hline & Perceive & Recognize & Monitor & Reach & Operate & \\
\hline Pre-Usage & & 6 & 4 & 3 & 5 & 18 \\
\hline Usage & 2 & 6 & 3 & 1 & 2 & 14 \\
\hline Mid-Usage & & & 4 & & 1 & 5 \\
\hline Post-Usage & & & 1 & 3 & 1 & 5 \\
\hline Maintenance & 1 & & 2 & 5 & 9 & 17 \\
\hline Counts & 3 & 12 & 14 & 12 & 18 & 59 \\
\hline
\end{tabular}

\subsection{Created Personas}

We developed a total of eight personas covering the four target user groups of visually impaired, hearing impaired, spinal-cord-impaired, and elderly people. In the results, each group has two personas representing remarkable differences within the group: one for an archetypal case and the other for an atypical case. In other words, one persona in a group represents a well-known or often-considered case of disabilities or elderlies, while the other represents the case that may be considered rarely. Hence, the archetypal personas are blind, 
deaf, closed-fist, and grandma personas, whereas the atypical personas are low-vision, cochlear implemented, opened-palm, and grandpa personas, as shown in Figure 4.

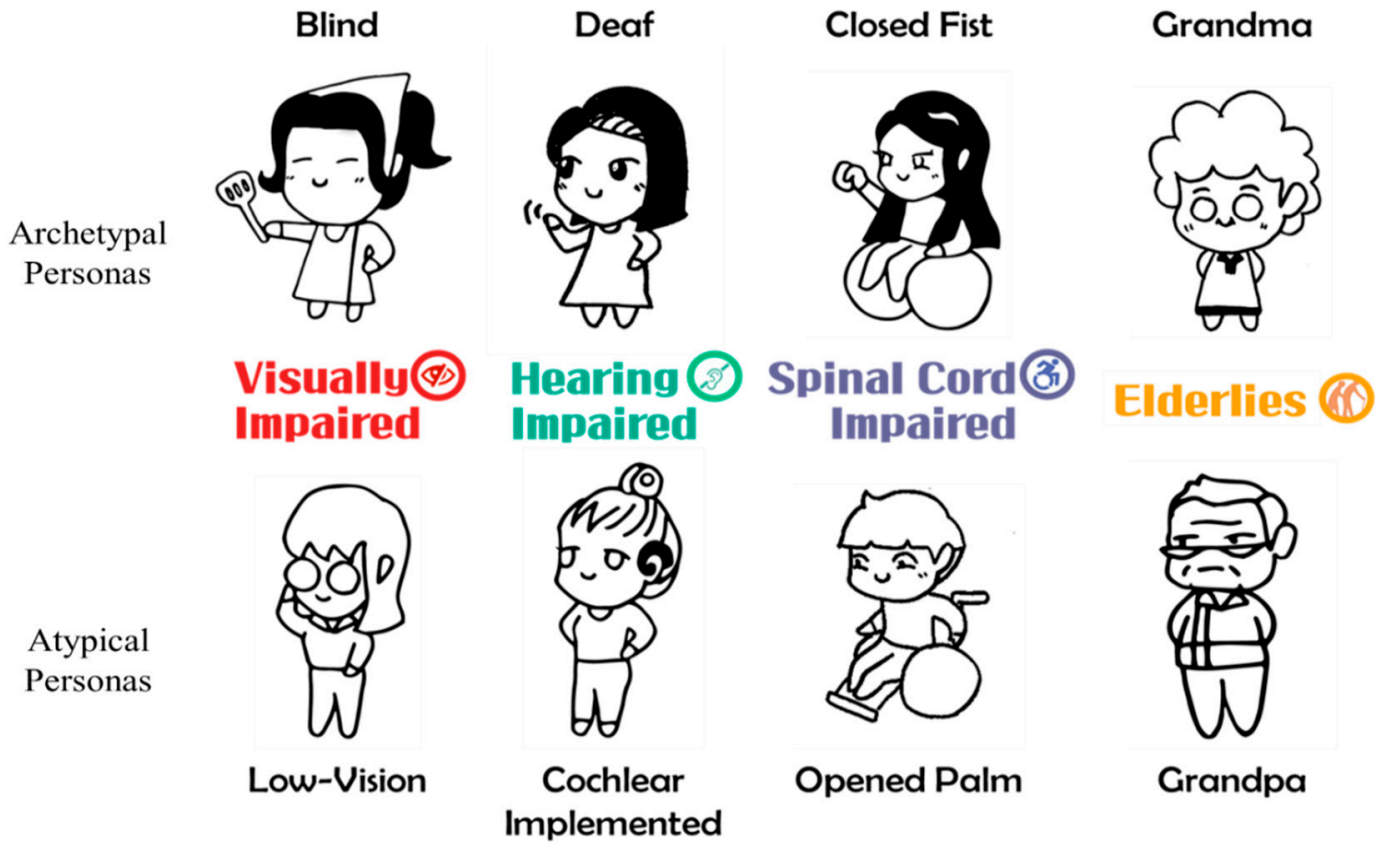

Figure 4. Eight personas created for four target user groups (archetypal and atypical personas).

As mentioned above, each persona is represented in a form of a persona card. For example, Ms. Suzy is the archetypal visually impaired persona representing the blind users. As shown in Figure 5, Her persona card describes who she is on the left: her physical characteristics and how she uses them, an assistive device she uses, and family members. On the right side are her behavior and attitude toward home appliance usage along with a relevant quotation and accessibility issues. Her task barriers and goals are expressed iconically in terms of IEC 63008 tasks, in her case, they are perceive, recognize, and monitoring.

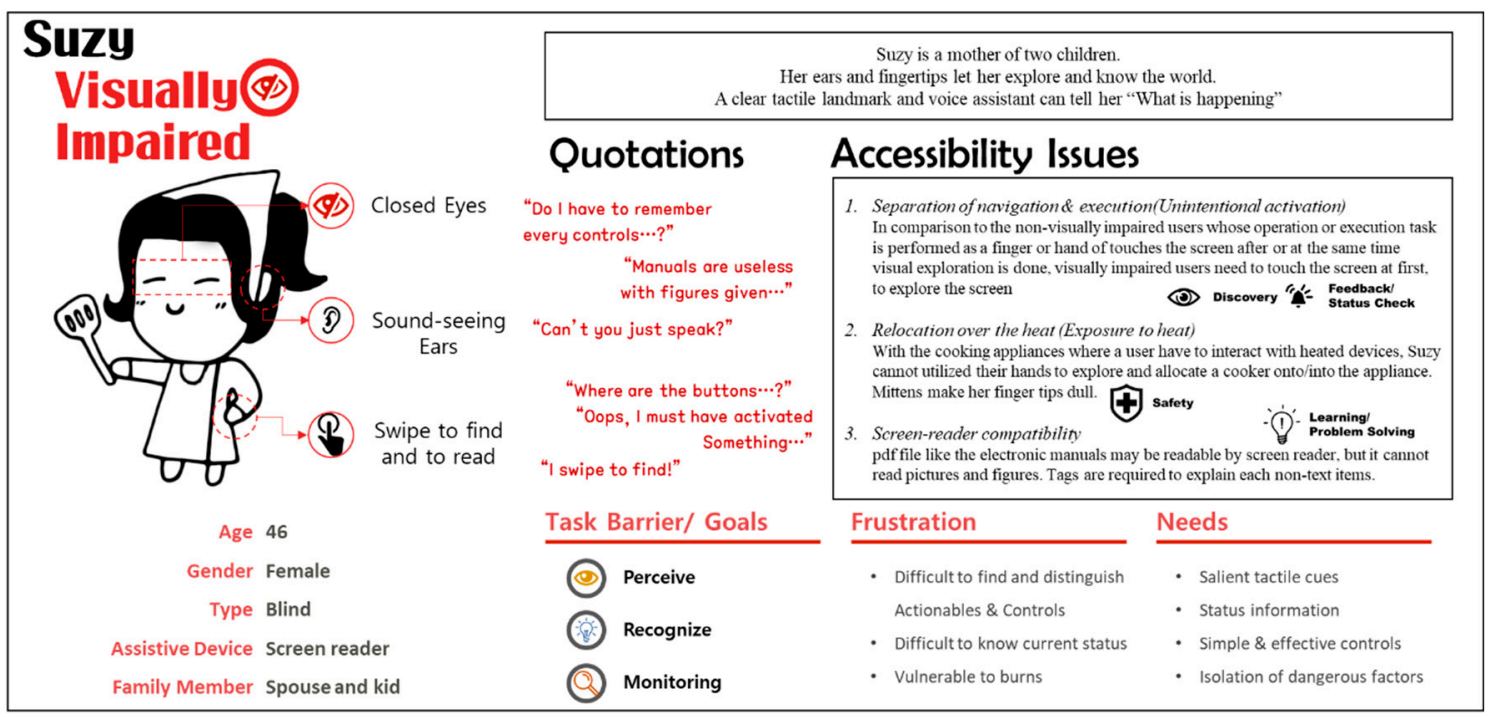

Figure 5. Persona card of Ms. Suzy, the blind persona.

At the bottom of her persona card is summarized her accessibility issues in a brief manner-frustration and need. She is frustrated when the operable parts and controls are 
difficult to find or distinguish due to a lack of auditory explanation and tactile cues. In addition, she struggles to comprehend the current status of home appliances, whether it is running or how it changed after her control inputs. Suzy is also more susceptible to burns since some of the home appliances related to cooking deal with the heat but her awareness cannot protect her enough due to limited monitoring capability. Moreover, her quote, "manuals with many figures are useless" represents the incompatibility of her assistive device: a screen reader. Unless there are corresponding tags given to explain the figures in a screen-reader in compatible text-form, she cannot access any relevant information. The rest of the personas with persona cards are provided in Appendix A.

\section{Discussion}

The accessibility issues regarding the five accessibility tasks and operational phases allow a manufacturer to grasp the relative frequencies for issue occurrence within the context of home appliance usage. In Table 4a-d, regardless of this relative difference in numbers, one must not assume that the severity of the disability caused the difference in total issue counts, but keep in mind that it took longer for the hearing impaired group to share their experience within a limited interview time since it required a sign language translator to translate their opinions simultaneously. In contrast, the visually impaired and spinal-cord-impaired groups could verbally express their issues, allowing them to utilize the interview time more. In this section, we defined the distinctive behaviors and characteristics of personas and discussed corresponding accessibility issues.

\subsection{Behaviors and Characteristics of Personas}

This section explains the basis of persona segregation within each user group. Each persona representing eight different user types describes its general yet unique behaviors and characteristics under the context of home appliance usage (see Appendix A). The difference between the archetypal personas and atypical personas are discussed.

\subsubsection{Personas with Visual Impairments}

The personas for visual impairments are the blind persona and low-vision persona. When people generally think of a visually impaired person, they tend to think of a blind person and usually come up with basic ideas such as the implementation of braille, which is fully tactile-dependent yet excludes visionary solutions. However, one must not hastily assume that every visually impaired user can read braille [42], as $64 \%$ of the visually impaired participants have acquired disability as shown in Table 4 . Moreover, visually impaired people with low vision showed a high dependency on visual information though the visual information may not be lucid for them. It is important to include a low-vision persona when considering the accessibility issues for visually impaired people so that the idea generated can reflect a multi-modal information provision such as visual supports along with tactile and auditory supports. Thus, we provide common issues for both blind and low-vision personas, along with some dedicated issues per personas.

Ms. Suzy is the blind persona representing the archetypal visually impaired users. Her eyes are closed to represent that she is blind, while her ears are exposed to show that she highly relies on auditory sources. Her quotations and marks on her hand describe her swiping behavior when she explores the product. Ms. Suzy uses a screen reader as her assistive device, which is her verbal companion.

Ms. Jenny, as shown in Figure A2, is the low-vision persona representing the atypical visually impaired users. She wears glasses to represent that she does rely on visual sources. Her ears and hands are noted in the same manner as Ms. Suzy. She also swipes her hands over a product just like Ms. Suzy; however, she also approaches a product at a close distance so that she can visually see and comprehend. 


\subsubsection{Personas with Hearing Impairments}

The personas for hearing impairments are the deaf persona and cochlear implemented persona. The common misconception toward people with hearing impairments is that textual information can solve their information accessibility issues as mentioned above. Another common misconception is that installing a lighting feedback system can resolve their issues. This misconception disregards the context when the users are far away or turned away from the product, which frequently happens with home appliance usages; users do not stand right in front of the appliances all the time while they are running in peration.

Ms. Michelle is the deaf persona representing the archetypal hearing-impaired users. Her ears are covered by her hair and not exposed to show that she does not rely on auditory feedback, as shown in Figure A3. In contrast, her eyes are well-shown, and so are her hands, because she utilizes them well. Moreover, her hands are wiggling and her quotations are simpler in vocabulary to represent that she is a sign language user. A sign language user usually has comparably smaller vocabulary, since the language spoken in their nation is not their mother tongue, but sign language is. Moreover, sign language vocabularies are not fully compatible with common dictionaries. Sign language users tend to have a smaller vocabulary as if they are foreigners [43].

Ms. Elaine is the cochlear implemented persona representing the atypical hearingimpaired users. As shown in Figure A4, she has a cochlear implant on her ear, and her hairs are tied in the shape of zero and one, representing digital signals because the cochlear implant device converts outer acoustic sound into a digital signal which stimulates her auditory neurons so that she can hear the sound from her circumference. In contrast to Michelle, Elaine's quotations have complete grammar, and she does not wiggle her hands since she prefers to communicate verbally instead of with sign language.

\subsubsection{Personas with Spinal-Cord Impairments}

The archetypal and atypical personas for spinal-cord impairments are closed-fist persona and opened-palm persona, respectively. Other personas are segregated in terms of sensational dependency or difference in household work experience, whereas the personas of spinal-cord impairments are segregated based on their hand shapes: closed fist and opened palm. Anatomically or physiopathologically, it would be sensible to segregate spinal cord impaired personas based on the damaged area on their spinal cord, which causes a different level of neural communications via their spine [44,45]. Thereby, the level of freedom on the upper limb would have named personas such as tetraplegia with C6 injury or paraplegia with T6 injury or L1 injury. However, such names are too technical for the stakeholders to easily comprehend the specific characteristics of personas. In addition, tetraplegia user with C6 injury is simply in worse condition than the paraplegia with T6 injury with lower sensory level and less freedom of body movement [45], so the difference among personas would be rather minimal, and one persona can inclusively embrace all the issues of the other persona.

The reason for creating two different personas for a disability type is to represent different frustrations and needs within the disability group. As we observed and interviewed the real users with spinal cord impairments, the difficulties in the use of lower back to bend, to reach an object or operable located below or far, or to obtain visual access with limited sight were common throughout the users. However, hands were used, depending on their hand shapes when operating different types of operable parts like controls, doors, etc. Closed fist users needed wider clearance for their fist to go through, while opened palm users required deeper clearance. Moreover, each persona has the opposite gender with height difference to emphasize the accessibility issues that might occur due to physical differences, such as the difference in height reach and sight.

Ms. Tyra, the closed-fist persona, and Mr. Charles, the opened-palm persona, are the archetypal and atypical personas for the spinal cord users, respectively. The closed-fist type of disabled user is addressed in the ADA checklist [8], while the opened-palm type 
of user is not; the opened-palm user is often not considered. Thus, we defined Tyra, the closed-fist persona, as the archetypal persona for spinal cord impaired users.

As shown in Figure A5, Ms. Tyra is short in height, and sitting in a wheelchair makes her shorter and therefore less able to perceive items or appliance compartments located above her eye level, without extending her neck. Her hands are stiffened in the shape of a fist, requiring wider clearance for her whole fist to go through when she tries to operate an appliance in particular. Also, her fist does not allow her to precisely control a button or touch type interface, resulting in unintentional activation. She prefers to have an appliance that allows her to utilize both of her hands since it is not easy to grasp or hook her fist through a handle, especially by one hand.

Mr. Charles from Figure A6 is comparably taller than Tyra, making it harder for him to perceive or reach items located on a floor. A longer arm may allow him to reach further and higher, but his thicker body requires larger clearance than Tyra. Moreover, his hands stiffened in the shape of an opened palm, requiring longer and deeper clearance to operate an appliance. Moreover, his fingers are more vulnerable to being jammed.

\subsubsection{Elderly Personas}

Both elderly personas share many characteristics and issues with other user groups. For example, their diminished sensation correlates with the disabled sensation of visually impaired and hearing-impaired users. Furthermore, their diminished physical capability correlates with that of spinal-cord impaired users. However, certain points make elderlies distinctive from the other groups. The expertise and experience in household work mainly segregate the elderly personas into two: grandmother persona and grandfather persona. Although the grandmother persona may be weaker in strength and shorter in reach and height, she is more experienced with the household work, so she can operate most of the appliances as long as they work in a fashion familiar to her. On the other hand, the grandfather persona is physically taller and stronger, yet his knowledge of the household is far behind that of the grandmother persona. Both personas struggle from diminished abilities to see, hear, and move at a low level [35,46-48], and they prefer dials and buttons to touch screens since they are not familiar with the new technologies like ICT devices [21,22,49-51].

Mrs. Pauline from Figure A7 is the grandma persona representing the archetypal elderly user. She is comparably shorter in reach and height, and she is weaker in strength. She also suffers from light dementia [51]; she keeps forgetting what she was doing. Moreover, the prevalent neologisms throughout the control panel of home appliances makes it harder for her to memorize their functions.

Mr. Donald is the grandpa persona representing the atypical elderly users, shown in Figure A8. He is comparably taller and stronger than Mrs. Pauline, but weaker than the younger users; he can be categorized as a "fit older person" from a previous study [51]. He suffers from hearing loss along with his diminished vision; he tends to miss both visual and auditory alarms. It has been a long time since he did household work, and the modern home appliances evolved so much, making him re-learn everything. Although men participate more in household works these days [52], a study from two decades ago [53] confirmed that men are less participatory in household work, and Mr. Donald surely is from such an era. Moreover, this was verified in the interview, revealing their comparably lower expertise in household work than their female counterparts.

\subsection{Accessibility Issues from Personas}

There are various accessibility issues across eight personas; some share the same issues, while some have unique issues. There are at least two common issues and two persona-specific issues provided within each user group. The summarized accessibility issues are as shown in Figure 6. More specific accessibility issues are given in persona cards (see Appendix A). 


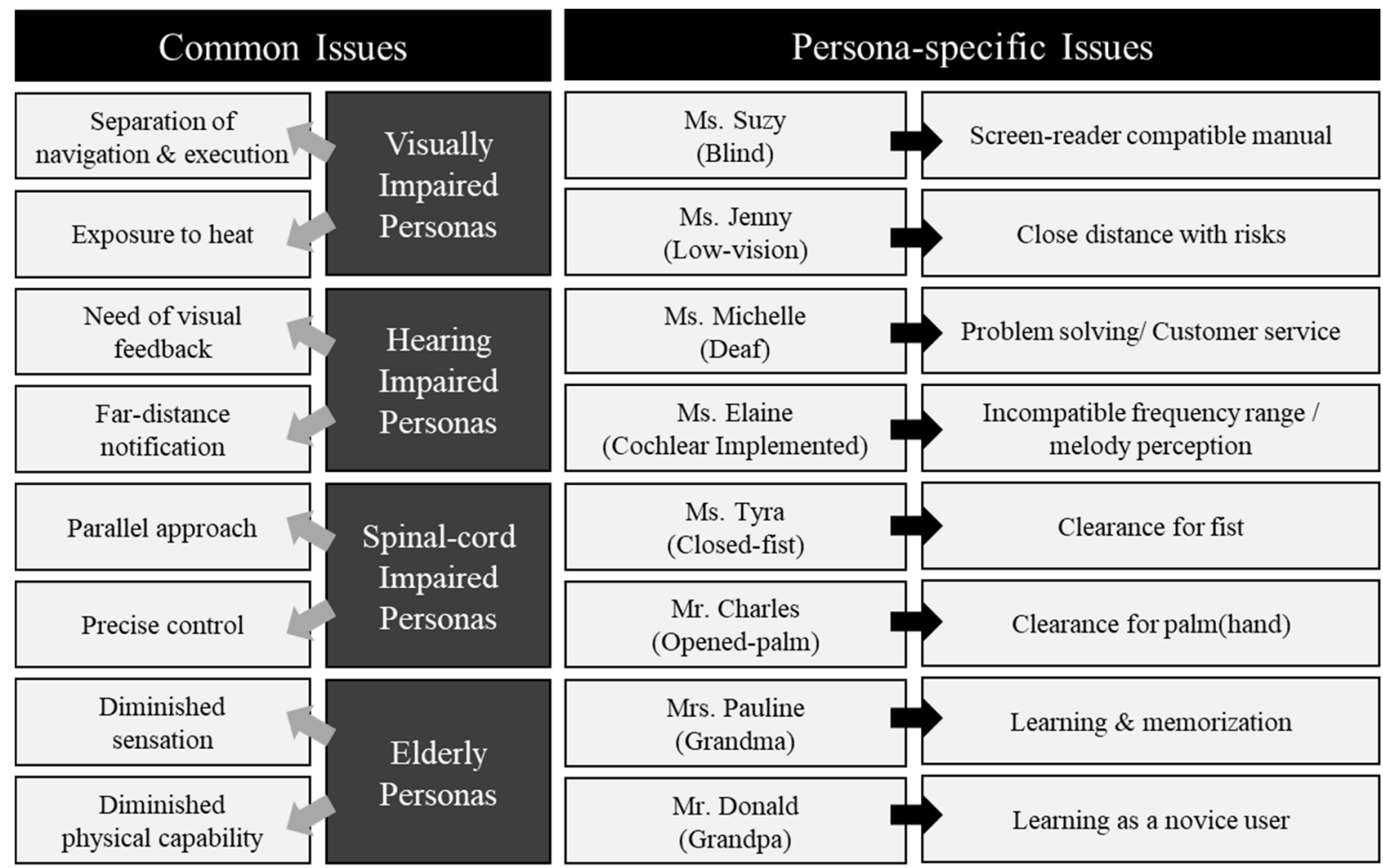

Figure 6. Accessibility issues of Personas-common and persona-specific.

As we scrutinize the issues of each persona to categorize them, there was a need to expand the five accessibility issues in the following seven terms: (1) discovery, (2) learning/problem-solving, (3) feedback/status-check, (4) reaching/posture, (5) grasping/control, (6) moving/lifting, and (7) safety. We used these seven terms representing the accessibility context-of-use shown in Figure 7 to categorize the accessibility issues. Their names are more task- and context-oriented and self-explanatory than those of IEC 63008 tasks.

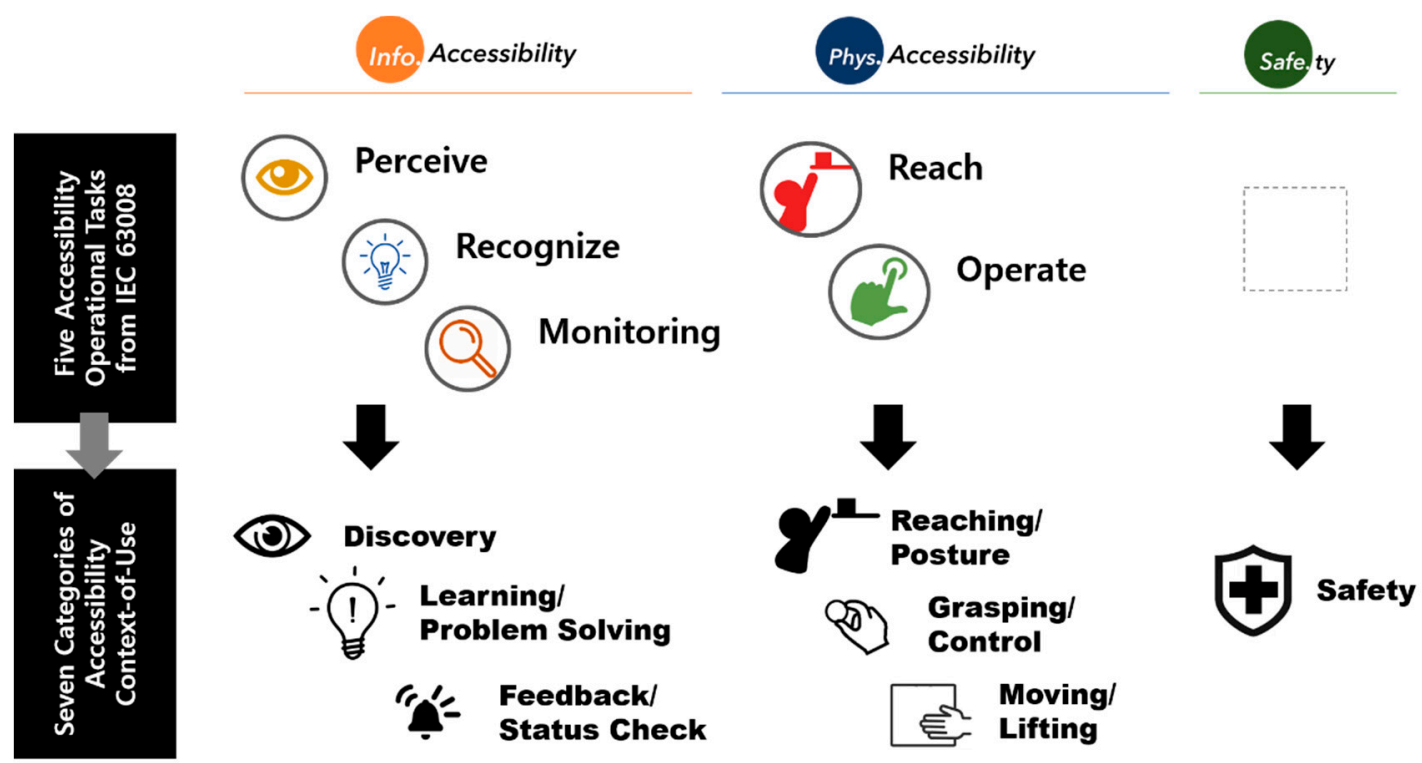

Figure 7. Seven categories of accessibility context-of-use expanded from the five tasks in IEC 63008.

Firstly, we have three informational accessibility terms: discovery, learning/problemsolving, and feedback/status-check. Discovery is equivalent to that of perceive; it repre- 
sents the searching task for information and product compartment of interest via sensory channels. The learning/problem-solving took a partial definition of recognize, and it is dedicated to the comprehension and planning for consequential tasks. Finally, the feedback/status-check is mostly equivalent to the monitoring task, yet it also partially borrows a definition from recognize to represent the identification task. Simplifying, we segregated the "recognize" task into two, merging one part and keeping the other independent.

For the physical accessibility terms, we have reaching/posture, grasping/control, and moving/lifting. Reaching/posture is equivalent to that of reach task. However, the positioning and grasping part of the reach task was taken apart from it and was merged with a part of the operate task, resulting in grasping/control. This required segregation because the reach issue and grasping/control issue could be investigated independently. Finally, the operate task was segregated into two; grasping/control and moving/lifting. The former part is merged with reach to become grasping/control as mentioned, and the latter stayed independent as moving/lifting. The operate task was a broad term that represented any arbitrary physical movement to achieve a user's goal. The segregation into control and movement could clarify the behavioral differences.

Finally, we added the term "safety", which was originally not included in the IEC 63008 tasks. There is a risk from heat since the users have to deal with the heat when using home appliances such as cooktops, ovens, and microwaves. Moreover, due to the slower reaction time of our target users, acuminate edges of moving parts may cause a safety issue as well. The safety term may seem to overlap with other terms since it occurs while a user performs an interaction related to the rest of the six contexts of use. However, the result is related to the safety of the user, whereas the results of other issues are related to the completion of a task. Therefore, the term safety is worth adding.

Based on these seven terms and relevant accessibility issues investigated, a list of checkpoints for accessibility issues in the home appliance context is given in Appendix B.

\subsubsection{Common Issues Across the Personas}

There were common issues found across the archetypal and atypical personas when using home appliances. There are a total of four accessibility issues related to the discovery and feedback/status-check, two accessibility issues related to reaching/posture and moving/lifting, one issue relevant to grasping/control and safety, and finally, one safety issue. There was no learning/problem-solving context across the common issues across the personas.

The discovery issue combined with the feedback issue is mostly related to the usage phase, where a user tries to find controls and operate them. Visually impaired personas can unintentionally activate the control parts as they swipe over a control panel [54-56]. Furthermore, this issue may occur more frequently because more modern appliances are equipped with touch screen interfaces [54,55]. However, an accessibility support feature with a voice assistant like a smartphone [54,56,57] can solve this issue by providing a unique strategy of separating the navigation and performance [58].

On the other hand, the information presented in a larger size, higher contrast, and given with multi-channel sensory methods [10,12,59] can be greatly appreciated by both the hearing-impaired personas and elderly personas with diminished sensation. Moreover, especially for the hearing impaired, it may be beneficial to provide tactile feedback with a wearable device when they need noticeable feedback at a far distance from home appliances. The wearables are always in contact with a user $[60,61]$, unlike a smartphone sitting on a counter or a table $[62,63]$. Tactile feedback can draw their attention much quicker and efficiently [64]. This solution can also be in the same domain of solution for visually impaired personas.

In terms of physical accessibility issues, both the spinal-cord-impaired and elderly personas have difficulties in reaching/posture and moving/lifting context. The main reasons for this issue are the awkward posture created by the parallel approach [8] taken by 
the spinal-cord-impaired personas and diminished physical capability of elderly personas. Moreover, both the spinal-cord-impaired and elderly personas are comparably slower in reaction time or longer control time-the grasping/control issue. The spinal-cord-impaired personas have stiffened hands, and accordingly, it is challenging for them to grasp or precisely maneuver a control device [65-68].

Finally, there was a safety issue found across both visually impaired personas. They encounter re-loading/re-allocation issues during the mid-usage phase under the home appliance context. Specifically, a user interacts with heated utensils or appliances without noticing which part is hot or not. Both blind and low-vision personas cannot utilize their hands to explore and allocate a cooker inside a heated home appliance. One of the interview participants said, "I can wear mitten, but the sensitivity of my fingertip becomes dull." Such an issue hinders the users from successfully following a cooking recipe and discourages them from using the appliance.

\subsubsection{Persona-Specific Issues}

Four out of eight persona-specific issues were related to the learning/problem-solving context. These issues may seem alike. However, they were different in terms of the aforementioned criteria: (1) the differences in the level of utilization of disabled/diminished parts, (2) physical differences, and (3) differences in experience and attitude regarding the use of home appliances. The learning/problem-solving issue is a severe problem in terms of autonomy because it requires not only the use of an assistive device but also help from others. In other words, a solution to this issue can drastically enhance the autonomy of the elderly and disabled users.

Reading a manual is problematic when the blind persona-Ms. Suzy-wants to learn about the appliances. Most manufacturers these days provide an electronic copy of manuals so that visually impaired people can read them via their screen readers. However, many of them miss providing tags of explanation for figures in manuals. Screen readers cannot read something that is not textified, and the readers are not compatible with manifold pictorial figures to read them like a text [54]. Moreover, manuals are simplified in terms of text, not providing enough information for the blind persona when they cannot refer to pictorial figures. Therefore manufacturers must provide screen-reader-compatible manuals.

On the other hand, Ms. Michelle, the deaf persona, encounters difficulties in problemsolving when an error occurs. Error codes are mostly in incomprehensible form, and manuals are useless because they are written in a verbose and untranslatable manner for sign language users. When an error that cannot be solved by a user alone occurs, the user will feel frustrated and discouraged from using the product. Such an issue can frequently occur as there can be unintentional activation from a deaf user who cannot hear feedback from what one activated. Eventually, this can cause an error or error-like incomprehensible state of an appliance. Michelle cannot ask for help from a customer service agent since she cannot make a phone call $[24,69]$-verbally. When an error that cannot be solved by a user alone occurs, the user will feel frustrated and discouraged from using the product. Such an issue can frequently occur because there can be unintentional activation from a deaf user who cannot hear feedback from what one activated. Eventually, this will cause an error or error-like incomprehensible state of an appliance. In response, a manufacturer can implement $Q R$ codes on their appliances for sign-language-compatible video manuals if they cannot afford to have a sign language translator in their customer service department $24 / 7$.

For the elderly personas, it is challenging for Mrs. Pauline to adopt a new technology or learn about it. This is not only due to the fear of using an ICT device [21,22] but the light dementia she suffers as well. Such memory loss combined with incomprehensible neologism used in modern appliances makes it harder for her to memorize all the function names written in the control panel of home appliances. She is therefore restricted to use the one function that she frequently uses. Furthermore, she tends to forget about the household works she was doing due to light dementia [51], so she is also exposed to possible risk and 
repetitive work; mild color coding on controls and timers with alarm for safe use can help her $[10,12,59]$.

On the other hand, Mr. Donald also suffers from learning home appliances but for a different reason. He has comparably short experience of doing household work or using home appliances. It is cumbersome to know which part corresponds to a specific feature or function since he is not familiar with products and their structures. However, his obstinate personality does not allow him to ask for help from others. Nevertheless, his diminished visual and hearing capability hinders him from proceeding with the task without a doubt. He is simply a novice user; the appliances must be more intuitive and self-explanatory.

The persona-specific issue under the feedback/status-check is assigned to Ms. Elaine, the cochlear-implemented persona. A hearing-impaired person with a cochlear implementation does rely on auditory information similar to how a low-vision person also dependent on visual information. The cochlear implant is optimized for the vocal domain frequency range, which is narrower than that of music or melody [70-72]. Many home appliances implement non-verbal auditory-feedback, which have a frequency domain beyond the optimized domain of a cochlear implant, resulting in an incompatible frequency range for Ms. Elaine. Therefore, home appliances with auditory feedback should allow such users to customize the frequencies of feedback alarms at their preference, in other words, at their perceivable range.

For the reaching/posture and grasping/control issues, both the spinal-cord-impaired personas have dedicated clearance issues. These two personas require two different design approaches, though both the issues point toward the clearance issues. Therefore, they are sorted as persona-specific issues. The closed-fist persona (Ms. Tyra) has difficulties in pushing through a button that is flushed to the surface of an appliance when the button clearance is narrower than the size of her fists. In this case, Tyra cannot fully push the button to activate an operable part. Furthermore, most of the handles-even the protruding bar type-do not provide enough clearance for her fist. Therefore, Tyra-the closed-fist type-requires a clearance design based on her fist circumference unless she can hook her wrist on an operable without her fist interfering.

On the other hand, for the opened-palm persona (Mr. Charles), it may seem more accessible to achieve operation in comparison to Tyra's case. The clearance design for him is based on his fingers or hand blade size, which are comparably smaller or thinner than the fist circumferences. However, his fingers can be unintentionally hooked into a groove, which eventually hinders his intended movement or action. The fingers of Charles will prevent doors from opening like a hinge lock. The gap between the two handles should be wider than his finger length or hand length.

Lastly, there is a safety issue for the low-vision persona. A previous study [73] and the observation we conducted demonstrated that the lower-vision users have shorter viewing distances than those of normally sighted users, meaning they have a closer distance to interact with devices. Under the home appliance context, this means they are in close contact with possible risks such as heat and abruptly moving parts-especially when considering unintentional activation is one of the other issues they have.

\section{Conclusions}

This study aims to investigate accessibility issues under the context of home appliance usages for the target user groups: visually impaired, hearing impaired, spinal cord impaired, and elderly users. Consequently, we reformed the data collected from the FGI and observation into eight different personas to help stakeholders deeply comprehend and empathize with their users, instead of letting them proceed with stereotypical misconceptions of their target users. Any stakeholders who have not contacted their users with disabilities can have stereotypical misconceptions about their users. They might impetuously conclude that a person with visual impairment will need braille, that a person with hearing impairment can read instead if not heard, that people with a spinal cord impairment only need knee clearance for their wheelchairs, and that elderly people are 
not active in household work. In addition, designers and manufacturers tend to think of direct resolution under the engineer's perspectives [74] before they adequately scrutinize and define the problem at a deeper level to investigate the actual needs. When the target users are disabled or elderly users whom they do not yet understand, the situation only gets worse. Therefore, this study aims to deliver personas of disabled and elderly users so that the stakeholders not only overcome the difficulties in recruitment but also derive resolutions with clarified and well-defined accessibility problems.

Surely, this study result does not mean that real user involvement is unnecessary when personas are created. However, personas can play a role as a cognitive guideline before conducting a user study on a vulnerable population from scratch. The persona can be used in not only the early stage of product development but also in the later stage, as a scenario of using a newly developed product can be evaluated based on the personas. Personas help manufacturers to narrow down, specify, and define issues with their target users, which would allow them to conduct more efficient and effective user studies. Again, the persona is a user research method for problem definition. Problem definition is more critical to develop an innovative product than solution generation because a well-defined problem can lead to clear solutions [75] throughout the overall product development process.

Although Schulz and Fuglerud [35] recommended creating personas for disabilities, a study from Goodman [18] pointed out that the focus on stereotypical users can make it hard to communicate detailed information about the range of abilities within a population; thus, personas may provide a limited amount of information only. However, this study provided two types of personas for each user group of disabilities and elderlies to represent the range of abilities within each user population. Each persona spoke of themselves; who they are, how they interact with home appliances, and what they need across all the usage phases from pre-usage to maintenance. There were various accessibility issues, which were both expected and unexpected within their first mile to last mile of usage. Moreover, under the context of home appliance usage, we believe these personas create social links and rapport for stakeholders to empathize with the personas as individuals of a family or neighbors sharing the same life routines-using the same types of home appliances but with difficulties - since the home appliances are the everyday product.

It is undeniable that home appliances are everyday products in general since we use home appliances on a daily basis: to cook, to keep our food being stored, to wash our clothes, and so on. However, are home appliances really the "everyday product" for the disabled and elderly population as well? According to ISO 20282-1 [76], the definition of an everyday product is a consumer product or walk-up-and-use product designed for use by members of the general public. Unless the term "general public" is to discriminate against the disabled or elderly population, a simple statement like "home appliances are everyday products" must remain true for the disabled users as well; however, this is not presently the case. To design a home appliance that is truly an everyday product, manufacturers and designers are responsible for considering the disabled population in their mind throughout product development; this needs more attention from manufacturers.

Existing studies confirmed that there is a large population of interest for investment from stakeholders. The lack of accessible products for disabled users provides an opportunity for stakeholders like manufacturers and designers to seize a large number of customers whom their competitors missed out on, leading to profitable ventures. The disabled population will be loyal to products whose design considers their needs and frustrations, especially when they can reclaim and appreciate the benefits they have been missing. Hence, it will be a blue ocean for stakeholders to expand their market shares [77]. Stakeholders can benefit from studying disabled users to obtain latent user needs and product innovation when they consider disabled users as lead users [62,78,79]. Overall, there are adequate reasons for stakeholders to study disabled users.

There are two limitations of this study in terms of implication. Firstly, the personas we created may be applicable to represent the users who have had their disability for the long term. This study asked the participants whether their disabilities are acquired or 
congenital. However, the difference was the key factor in neither persona segregation nor the accessibility issue. This may imply that the participants who acquired their disability would have been in the same condition for a long time. On the other hand, the users who newly acquired a disability may have different accessibility issues when compared to users with long-term or congenital disabilities. Unfortunately, the data on impairment duration was not collected in this study; therefore, such a difference could not be investigated. However, such segregation, on top of the archetypal and atypical segregation made in this study would have created too many personas, which is not manageable. Still, we highly recommend investigating meaningful insights on the behavioral differences and consequent differences in accessibility issues within the same user group in a future study.

Secondly, the personas created for this study may be applicable in the domain of home appliance design. This is because any persona created has its dedicated purpose and context-of-use; therefore, its application can be limited in a certain context. However, in a future study, we believe it is possible to recycle the personas-especially the persona skeletons - created in this study, by implementing proper task analysis with representative tasks such as the five assessment tasks of IEC 63008. Although previous studies stated that it is not recommended to recycle personas in order to engage stakeholders to know and to empathize with the personas $[35,80]$, a persona with fixed characteristics must be able to interact with multiple products, just like a real user whose characteristics remain constant interacts with multiple products if a persona truly represents a potential real-user. We believe that a persona correspondingly provides new insights or problematic issues in various contexts confirms that the persona really represents the real user, and it can be reused or recycled for other contexts of use and product usage cases. Furthermore, it can be more valuable to recycle the personas of disabled users created in this study as either skeletons of personas or ad hoc personas to start with for other contexts of use or projects, since the stakeholders will encounter the recruitment issue whenever they try to conduct new user research.

Author Contributions: Conceptualization, J.H.L. and Y.M.K.; methodology, J.H.L. and Y.M.K.; validation, I.R. and Y.M.K.; formal analysis, I.R. and J.H.L.; investigation, J.H.L.; resources, M.H.Y.; data curation, Y.M.K.; writing—original draft preparation, J.H.L.; writing—review and editing, I.R. and M.H.Y.; visualization, J.H.L. and Y.M.K.; supervision, I.R. and M.H.Y. All authors have read and agreed to the published version of the manuscript.

Funding: This research received no external funding.

Informed Consent Statement: Informed consent was obtained from all subjects involved in the study. Data Availability Statement: Data sharing not applicable.

Acknowledgments: This research was supported by Samsung Electronics Inc., and the authors deeply appreciate the administrative support for this work from the Institute for Industrial Systems Innovation of Seoul National University. We'd also like to confirm the special thanks to all the interview participants and the sign language interpreters.

Conflicts of Interest: The authors declare no conflict of interest. 


\section{Appendix A}

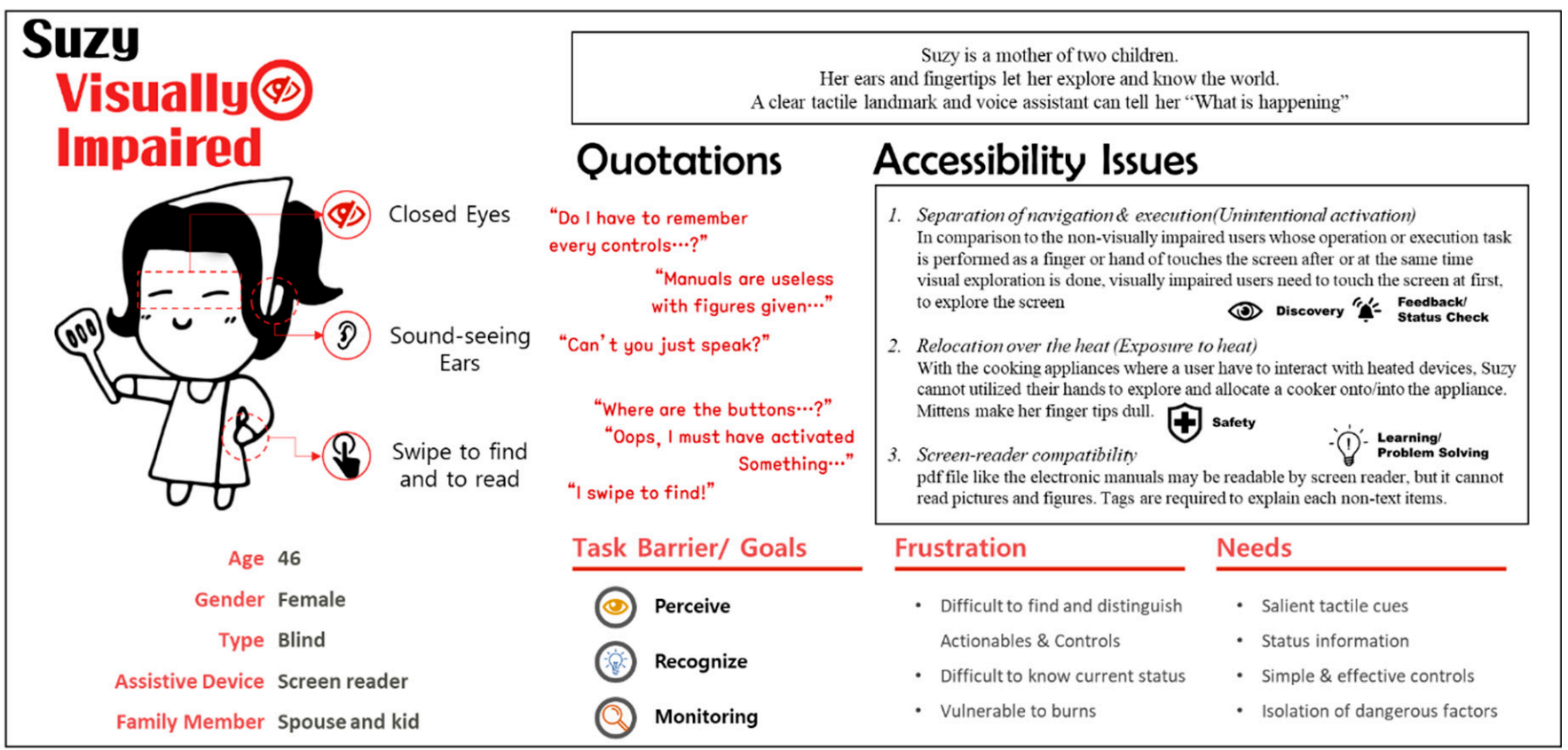

Figure A1. Persona card of Suzy, the blind persona.

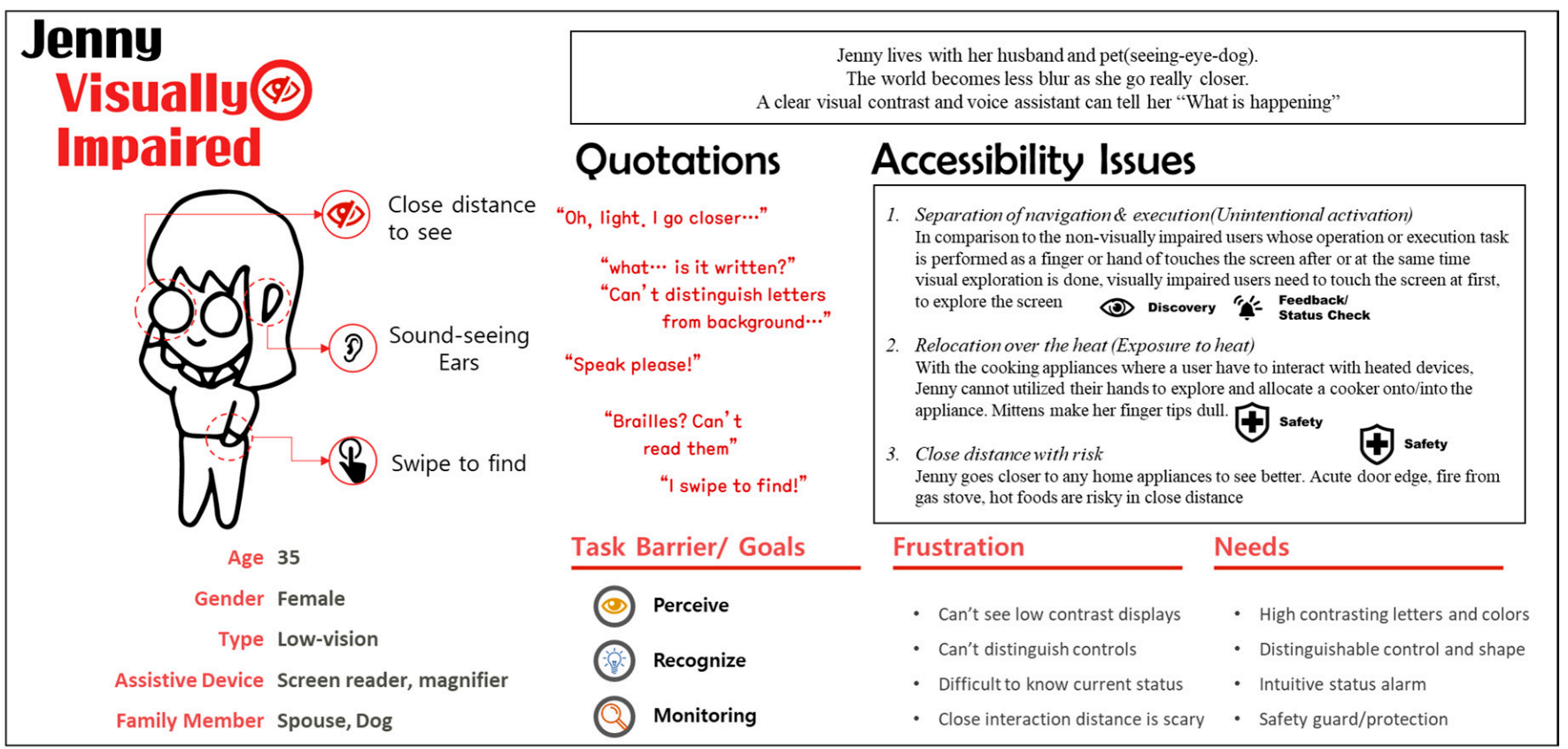

Figure A2. Persona card of Jenny, the low-vision persona. 


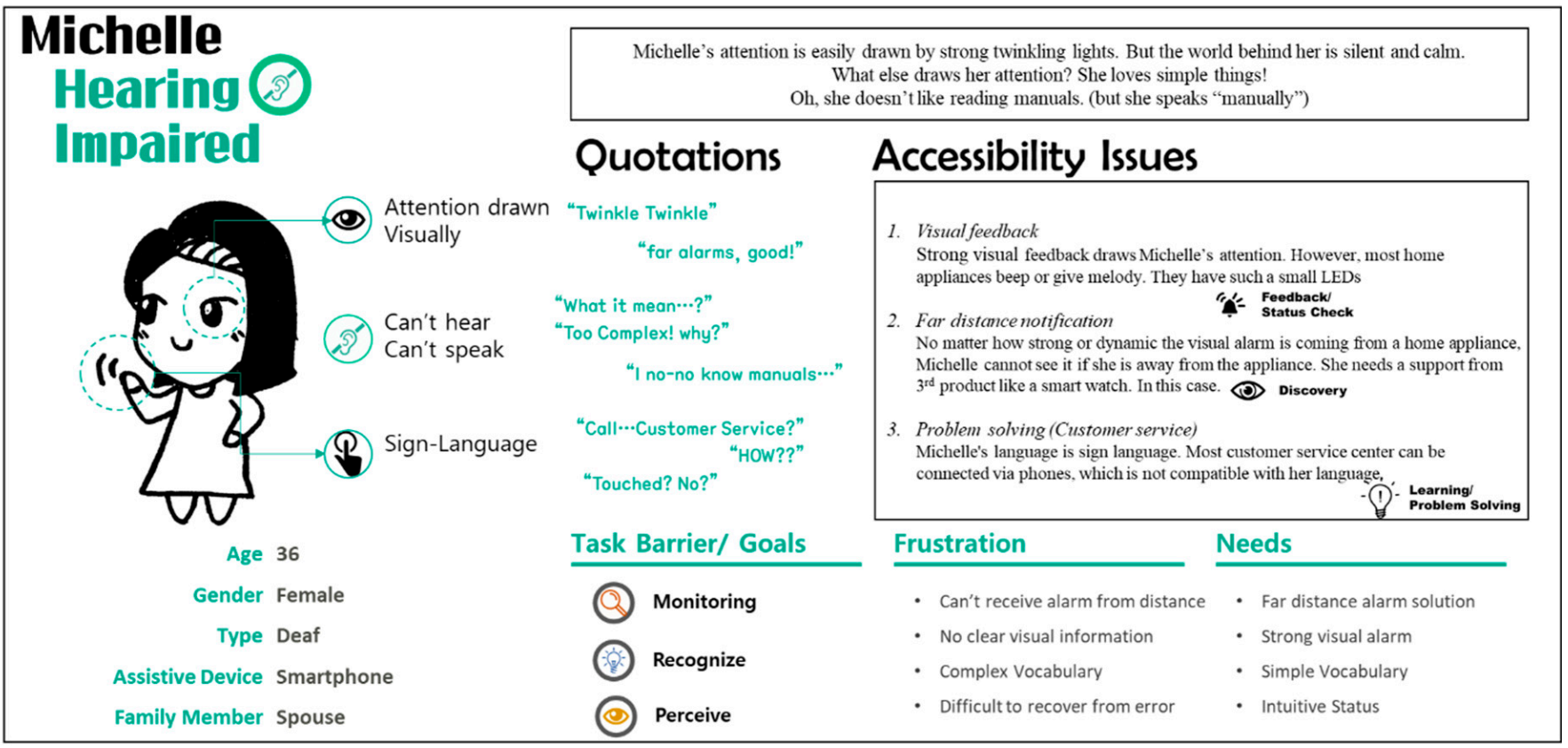

Figure A3. Persona card of Michelle, the deaf persona.

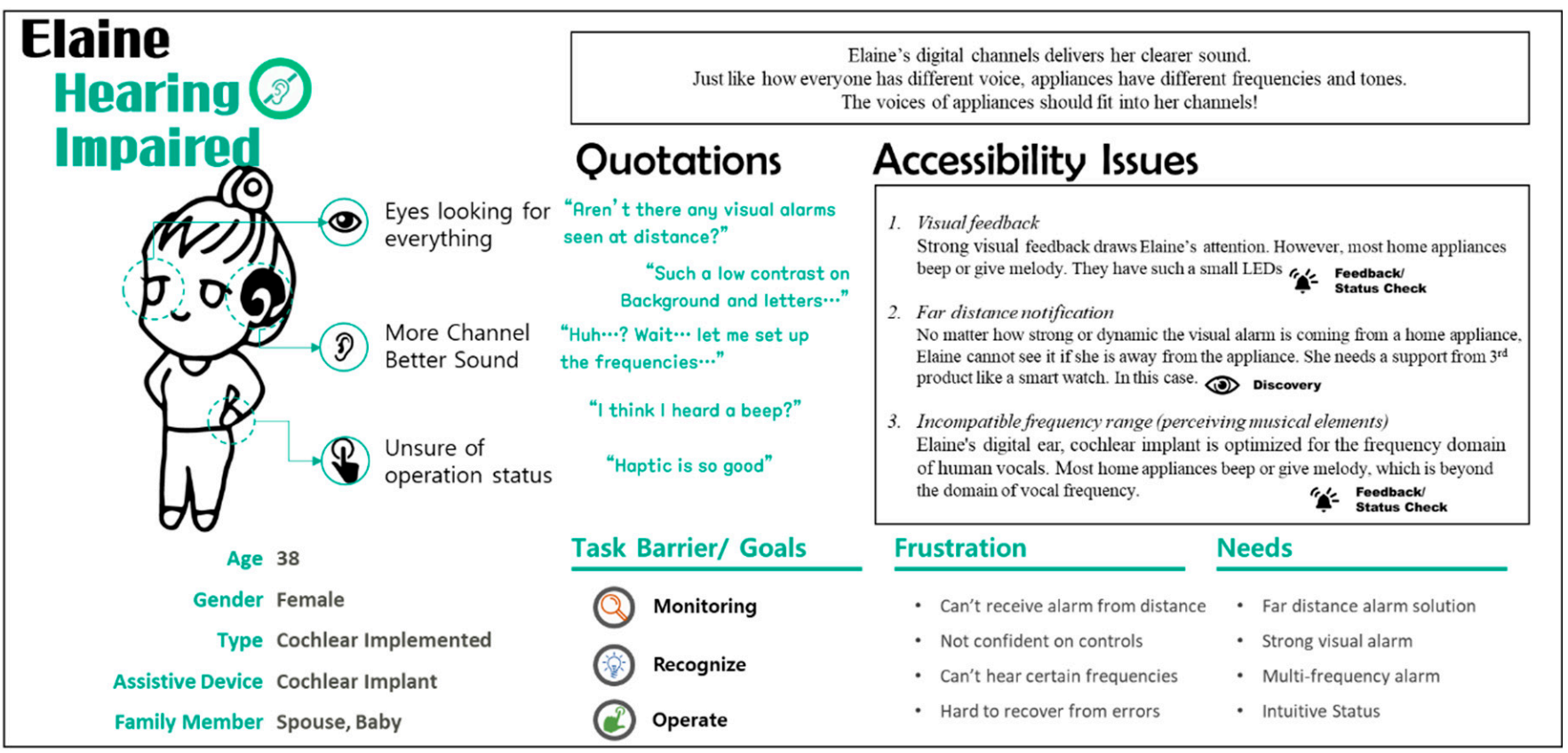

Figure A4. Persona card of Elaine, the cochlear-implemented persona. 


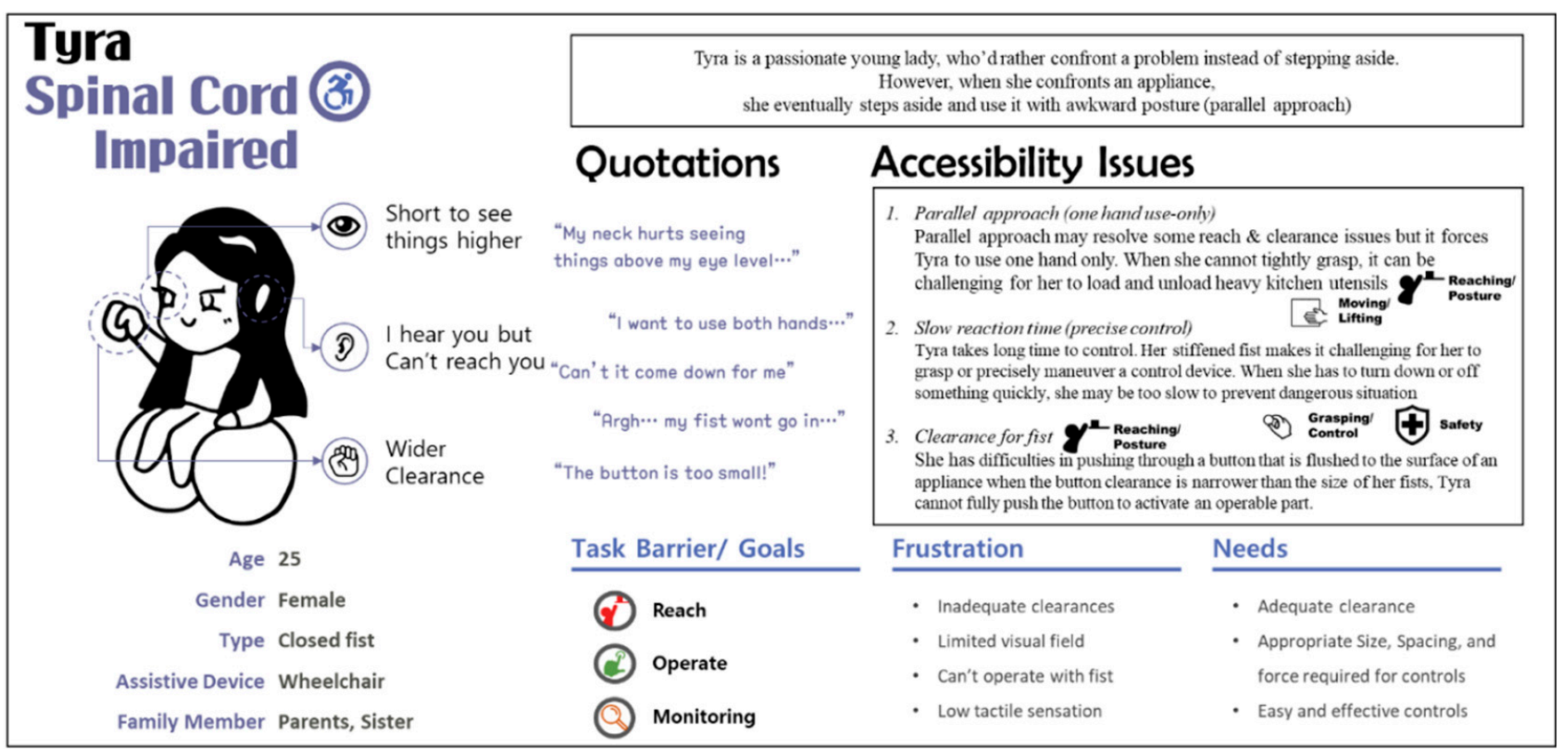

Figure A5. Persona card of Tyra, the closed-fist persona.

Limited lower "Can See, Can't Reach"
Field-of-view

Figure A6. Persona card of Charles, the opened-palm persona. 


Pauline considers herself a professional household worker.
Until she thet a speaking preduct that she knows how to use all appliance out there.

Figure A7. Persona card of Pauline, the grandma persona.

\section{Donald}

\section{Elderlies (10)}

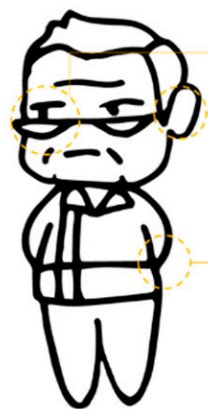

Age 73

Gender Male

Type Elderlies + hearing loss

Assistive Device Glasses, Hearing Aid

Family Member Spouse

Donald, after retirement, spends more time at home. All the household work used to be Pauline's, but not anymore. He bought new appliances to lessen the burden. He has never seen this kind and manuals don't help. He really meant to say, "old things are better"

Diminished
Vision

\section{Quotations}

"No one can read this!"

"So the manual says...

Pauline, help me here!"

5 Hearing

Strong

(Used to be)

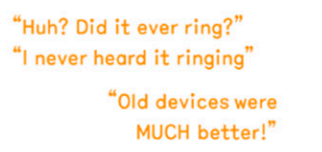

"Do I... Touch this?"

\section{Task Barrier/ Goals}
(C) Operate
(8) Recognize
(Q) Monitoring

\section{Accessibility Issues}

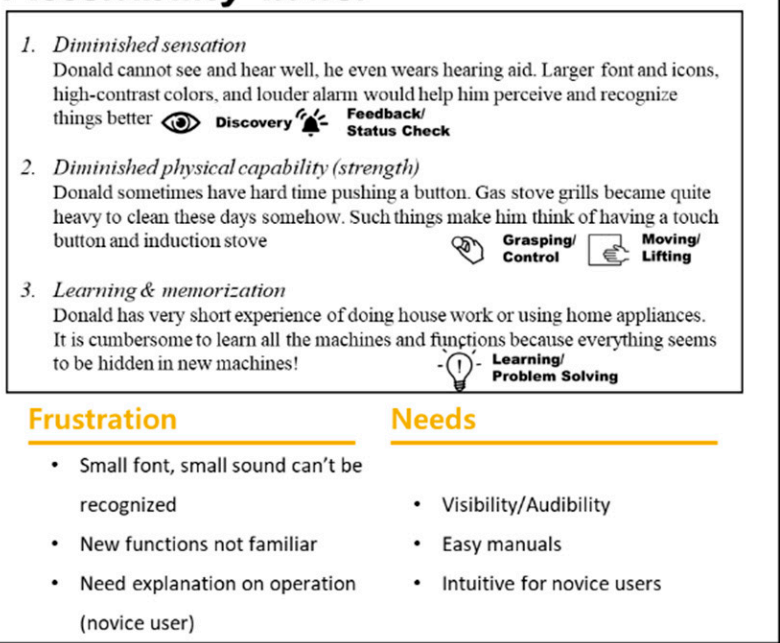

Figure A8. Persona card of Donald, the grandpa persona. 


\section{Appendix B}

Table A1. Accessibility checkpoints for the home appliance context.

\begin{tabular}{|c|c|c|}
\hline Accessibil & ntext-of-Use & Checkpoints \\
\hline \multirow{3}{*}{$\begin{array}{l}\text { Informational } \\
\text { Accessibility }\end{array}$} & Discovery & $\begin{array}{l}\text { - Can one successfully search for a target or } \\
\text { - } \quad \text { Can one successfully activate a target } \\
\text { function or control without } \\
\text { accidentally/unintentionally activating the } \\
\text { other surrounding components? }\end{array}$ \\
\hline & $\begin{array}{l}\text { Learning/Problem } \\
\text { Solving }\end{array}$ & $\begin{array}{l}\text { - Can one successfully learn or solve errors } \\
\text { without the help of others or an assistive } \\
\text { device? } \\
\text { Can one easily access the help (customer } \\
\text { center, manuals) that is compatible with } \\
\text { one's conditions? }\end{array}$ \\
\hline & $\begin{array}{c}\text { Feedback/Status } \\
\text { Check }\end{array}$ & $\begin{array}{l}\text { - Can one successfully distinguish a target } \\
\text { - Crom its surroundings? } \\
\text { current status from feedbacks by any } \\
\text { means? }\end{array}$ \\
\hline \multirow{4}{*}{$\begin{array}{c}\text { Physical } \\
\text { Accessibility }\end{array}$} & Reaching/Posture & $\begin{array}{l}\text { - Can one reach a target without an awkward } \\
\text { - } \quad \text { Can one reach a target without its } \\
\text { surroundings interfering? }\end{array}$ \\
\hline & Grasping/Control & $\begin{array}{l}\text { - Can one successfully maneuver a control? } \\
\text { - Can one utilize a contact grip (no grasp) } \\
\text { instead of grasping? }\end{array}$ \\
\hline & \multirow[t]{2}{*}{ Moving/Lifting } & $\begin{array}{l}\text { - Can one lift or move a target to the desired } \\
\text { location without excessive force? } \\
\text { Can one allocate a target without the need } \\
\text { for a precise maneuver? }\end{array}$ \\
\hline & & $\begin{array}{l}\text { - Can one be isolated from acuminate edge } \\
\text { or heat while using a home appliance? } \\
\text { - Any safety or automatic error-proof feature } \\
\text { built for user's safety? }\end{array}$ \\
\hline
\end{tabular}

Note 1: All these checkpoints must be checked with visually impaired, hearing-impaired, spinal-cord-impaired, and elderly users.

Note 2: All these checkpoints must be checked throughout all phases of usage: pre-usage, usage, mid-usage, post-usage, and maintenance.

\section{References}

1. World Health Organization. World Report on Disability; WHO: Geneva, Switzerland, 2011.

2. Dziura, J. Psychological Well-Being, Acceptance of Disability and Perceived Social Support. In US Military Veterans with Acquired Hearing Loss; Gallaudet University: Washington, DC, USA, 2017. 
3. Ellis, G. Impairment and Disability: Challenging Concepts of 'Normality'. In Researching Audio Description; Springer: Berlin, Germany, 2016; pp. 35-45.

4. Merkel, S.; Enste, P.; Hilbert, J.; Chen, K.; Chan, A.; Kwon, S. Technology acceptance and aging. Kwon S. (Hg.) Gerontechnol. 2016, $2,372$.

5. Buzzi, M.; Leporini, B.; Meattini, C. Design Guidelines forWeb Interfaces of Home Automation Systems Accessible via Screen Reader. J. Web Eng. 2019, 18, 477-512. [CrossRef]

6. Kim, H.K.; Kim, C.; Lim, E.; Kim, H. How to develop accessibility UX design guideline in Samsung. In Proceedings of the 18th International Conference on Human-Computer Interaction with Mobile Devices and Services Adjunct, Florence, Italy, 6-9 September 2016; pp. 551-556.

7. Ministry of Trade, Industry and Energy. 장애인·고령자도 가전제품 이용 쉬워진다-한국이 주도하는 '가전제품 접근성'국제표 준화 추진. In Easier Use of Home Appliances for Elderly People and People with Disabilities-Promotion of International Stand-Ardization of 'Accessibility of Home Appliance Products' Led by Korea; Ministry of Trade, Industry and Energy: Sejong City, Korea, 2014.

8. US Department of Justice. ADA Standards for Accessible Design; American Disability Association: Washington, DC, USA, 2010.

9. IEC 63008. Household and Similar Electrical Appliances-Accessibility of Control Elements, Doors, Lids, Drawers and Handles; International Electrotechnical Commission: Geneva, Switzerland, 2016.

10. ISO TR 22411. Ergonomics Data and Guidelines for the Application of ISO/IEC Guide 71 to Products and Services to Address the Needs of Older Persons and Persons with Disabilities; International Organization for Standardization: Geneva, Switzerland, 2008.

11. ISO 9241-20. Ergonomics of Human-System Interaction-Part 20: Accessibility Guidelines for Information/Communication Technology (ICT) Equipment and Services; International Organization for Standardization: Geneva, Switzerland, 2008.

12. ISO TR 29138-1. Information Technology_Accessibility Considerations for People with Disabilities_Part 1: User Needs Summary; International Organization for Standardization: Geneva, Switzerland, 2008.

13. ISO TS 16071. Ergonomics of Human-System Interaction-Guidance on Accessibility for Human-Computer Interfaces; International Organization for Standardization: Geneva, Switzerland, 2003.

14. Lewthwaite, S. Web accessibility standards and disability: Developing critical perspectives on accessibility. Disabil. Rehabil. 2014, 36, 1375-1383. [CrossRef] [PubMed]

15. Goodman, J.; Langdon, P.; Clarkson, P.J. Formats for user data in inclusive design. In Proceedings of the International Conference on Universal Access in Human-Computer Interaction; Springer: Berlin, Germany, 2007; pp. 117-126.

16. Segelström, F. Communicating through Visualizations: Service Designers on Visualizing User Research. In Proceedings of the First Nordic Conference on Service Design and Service Innovation, Oslo, Norway, 24-26 November 2009.

17. Kitchin, R. The researched opinions on research: Disabled people and disability research. Disabil. Soc. 2000, 15, 25-47. [CrossRef]

18. Goodman, J.; Clarkson, P.J.; Langdon, P. Providing information about older and disabled users to designers. In Proceedings of the HCI, the Web and the Older Population, Workshop at HCI, London, UK, 12 September 2006.

19. Daae, J.; Boks, C. A classification of user research methods for design for sustainable behaviour. J. Clean. Prod. 2015, 106, 680-689. [CrossRef]

20. Carmichael, A.; Newell, A.; Dickinson, A.; Morgan, M. Using Theatre and Film to Represent User Requirements; Royal College of Art: London, UK, 2005.

21. Laguna, K.; Babcock, R.L. Computer anxiety in young and older adults: Implications for human-computer interactions in older populations. Comput. Hum. Behav. 1997, 13, 317-326. [CrossRef]

22. Virokannas, H.; Rahkonen, M.; Luoma, I.; Sorvari, M. The 60-year-old female worker as user of new technology. Int. J. Ind. Erg. 2000, 25, 491-495. [CrossRef]

23. Kroll, T.; Barbour, R.; Harris, J. Using focus groups in disability research. Qual. Health Res. 2007, 17, 690-698. [CrossRef]

24. Balch, G.I.; Mertens, D.M. Focus group design and group dynamics: Lessons from deaf and hard of hearing participants. Am. J. Eval. 1999, 20, 265-277. [CrossRef]

25. Maguire, M. Methods to support human-centred design. Int. J. Hum. Comput. Stud. 2001, 55, 587-634. [CrossRef]

26. Kujala, S.; Miron-Shatz, T. Emotions, experiences and usability in real-life mobile phone use. In Proceedings of the SIGCHI Conference on Human Factors in Computing Systems, New York, NY, USA; 2013; pp. 1061-1070.

27. Winter, D.; Holt, E.-M.; Thomaschewski, J. Persona driven agile development. Build up a vision with personas, sketches and persona driven user stories. In Proceedings of the 7th Conference on Information Systems and Technologies (CISTI), Madrid, Spain, 20-23 June 2012.

28. Cooper, A. The Inmates are Running the Asylum: Why High-Tech Products Drive Us Crazy and How to Restore the Sanity; Sams: Indianapolis, IN, USA, 2004; Volume 2.

29. Grudin, J.; Pruitt, J. Personas, participatory design and product development: An infrastructure for engagement. Proc. PDC 2002, 2, 144-161.

30. Cooper, A.; Reimann, R.; Dubberly, H. About Face 2.0: The Essentials of Interaction Design; John Wiley \& Sons, Inc.: Hoboken, NJ, USA, 2003.

31. An, J.; Kwak, H.; Jansen, B.J. Personas for content creators via decomposed aggregate audience statistics. In Proceedings of the 2017 IEEE/ACM International Conference on Advances in Social Networks Analysis and Mining (ASONAM), Sydney, Australia, 31 July-3 August 2017; pp. 632-635. 
32. Lee, M.; Kwahk, J.; Han, S.H.; Jeong, D.; Park, K.; Oh, S.; Chae, G. Developing personas \& use cases with user survey data: A study on the millennials' media usage. J. Retail. Consum. Serv. 2020, 54, 102051.

33. Pruitt, J.; Adlin, T. The Persona Lifecycle: Keeping People in Mind Throughout Product Design; Elsevier: Amsterdam, The Netherlands, 2010.

34. Marshall, R.; Cook, S.; Mitchell, V.; Summerskill, S.; Haines, V.; Maguire, M.; Sims, R.; Gyi, D.; Case, K. Design and evaluation: End users, user datasets and personas. Appl. Erg. 2015, 46, 311-317. [CrossRef]

35. Schulz, T.; Fuglerud, K.S. Creating personas with disabilities. In Proceedings of the International Conference on Computers for Handicapped Persons, Linz, Austria, 11-13 July 2012; pp. 145-152.

36. Henry, S.L. Just Ask: Integrating Accessibility Throughout Design; Lulu.com: Madison, WI, USA, 2007.

37. Kelle, S.; Henka, A.; Zimmermann, G. A persona-based extension for massive open online courses in accessible design. Procedia Manuf. 2015, 3, 3663-3668. [CrossRef]

38. Fuglerud, K.S. Inclusive Design of ICT: The Challenge of Diversity; Faculty of Humanitites, University of Oslo: Oslo, Norway, 2014; p. 282.

39. Fuglerud, K.S.; Schulz, T.; Janson, A.L.; Moen, A. Co-creating persona scenarios with diverse users enriching inclusive design. In Proceedings of the International Conference on Human-Computer Interaction, Copenhagen, Denmark, 19-24 July 2020; pp. 48-59.

40. Hannay, J.E.; Fuglerud, K.S.; Østvold, B.M. Stakeholder Journey Analysis for Innovation: A Multiparty Analysis Framework for Startups. Lect. Notes Comput. Sci. 2020, 12189, 370-389.

41. Sulmon, N.; Slegers, K.; Van Isacker, K.; Gemou, M.; Bekiaris, E. Using Personas to capture Assistive Technology Needs of People with Disabilities. In Proceedings of the Persons with Disabilities Conference (CSUN), San Diego, CA, USA, 22-27 January 2010.

42. Lee, B.H.; Lee, Y.J. Evaluation of medication use and pharmacy services for visually impaired persons: Perspectives from both visually impaired and community pharmacists. Disabil. Health J. 2019, 12, 79-86. [CrossRef]

43. Seo, K.J. Error Analysis of Korean used by The deaf and Foreigners as Korean Learners. Biling. Res. 2013, 52, $221-242$.

44. American Spinal Injury Association. Standards for Neurological Classification of Spinal Injury Patients; American Spinal Injury Association: Richmond, VA, USA, 1984.

45. Maynard, F.M.; Bracken, M.B.; Creasey, G.; Ditunno, J.F., Jr.; Donovan, W.H.; Ducker, T.B.; Garber, S.L.; Marino, R.J.; Stover, S.L.; Tator, C.H. International standards for neurological and functional classification of spinal cord injury. Spinal Cord 1997, 35, 266-274. [CrossRef] [PubMed]

46. Cruickshanks, K.J.; Wiley, T.L.; Tweed, T.S.; Klein, B.E.; Klein, R.; Mares-Perlman, J.A.; Nondahl, D.M. Prevalence of hearing loss in older adults in Beaver Dam, Wisconsin: The epidemiology of hearing loss study. Am. J. Epidemiol. 1998, 148, 879-886. [CrossRef]

47. Pitts, D. The effects of ageing upon selected visual functions: Colour vision, glare sensitivity, field of vision and accommodation in ageing and human visual function. Mod. Ageing Res. 1982, 2, 131-160.

48. Gerson, L.W.; Jarjoura, D.; McCord, G. Risk of imbalance in elderly people with impaired hearing or vision. Age Ageing 1989, 18, 31-34. [CrossRef]

49. Harrington, D.L.; Haaland, K.Y. Skill learning in the elderly: Diminished implicit and explicit memory for a motor sequence. Psychol. Aging 1992, 7, 425. [CrossRef]

50. Koncelik, J.A. Aging and the Product Environment; Hutchinson Ross Publishing Company: Stroudsburg, PA, USA, $1982 ;$ Volume 1.

51. Gregor, P.; Newell, A.F.; Zajicek, M. Designing for dynamic diversity: Interfaces for older people. In Proceedings of the Fifth International ACM Conference on Assistive Technologies, Edinburgh, Scotland, 8-10 July 2002; pp. 151-156.

52. Sayer, L.C. Trends in housework. In Dividing the Domestic: Men, Women, and Household Work in Cross-National Perspective; Stanford University Press: Palo Alto, CA, USA, 2010; pp. 19-38.

53. Doucet, A. Gender equality and gender differences in household work and parenting. Women Stud. Int. Forum 1995, 18, 271-284. [CrossRef]

54. Grussenmeyer, W.; Folmer, E. Accessible touchscreen technology for people with visual impairments: A survey. Acm Trans. Access. Comput. (Taccess) 2017, 9, 1-31. [CrossRef]

55. Kane, S.K.; Bigham, J.P.; Wobbrock, J.O. Slide rule: Making mobile touch screens accessible to blind people using multi-touch interaction techniques. In Proceedings of the 10th International ACM SIGACCESS Conference on Computers and Accessibility, Galway, Ireland, 22-24 October 2008; pp. 73-80.

56. Hakobyan, L.; Lumsden, J.; O'Sullivan, D.; Bartlett, H. Mobile assistive technologies for the visually impaired. Surv. Ophthalmol. 2013, 58, 513-528. [CrossRef] [PubMed]

57. Vatavu, R.-D. Visual impairments and mobile touchscreen interaction: State-of-the-art, causes of visual impairment, and design guidelines. Int. J. Hum. Comput. Interact. 2017, 33, 486-509. [CrossRef]

58. Kim, H.K.; Han, S.H.; Park, J.; Park, J. The interaction experiences of visually impaired people with assistive technology: A case study of smartphones. Int. J. Ind. Erg. 2016, 55, 22-33. [CrossRef]

59. Connolly, M.; Wilson, A. Kitchen aids. Bmj Br. Med. J. 1990, 301, 114. [CrossRef]

60. Alkhalifa, S.; Al-Razgan, M. Enssat: Wearable technology application for the deaf and hard of hearing. Multimed. Tools Appl. 2018, 77, 22007-22031. [CrossRef] 
61. Jain, D.; Findlater, L.; Gilkeson, J.; Holland, B.; Duraiswami, R.; Zotkin, D.; Vogler, C.; Froehlich, J.E. Head-mounted display visualizations to support sound awareness for the deaf and hard of hearing. In Proceedings of the 33rd Annual ACM Conference on Human Factors in Computing Systems, Seoul, Korea, 18-23 April 2015; pp. 241-250.

62. Hannukainen, P.; Holtta-Otto, K. Identifying customer needs: Disabled persons as lead users. In Proceedings of the International Design Engineering Technical Conferences and Computers and Information in Engineering Conference, Philadelphia, PA, USA, 10-13 September 2006; pp. 243-251.

63. Hermawati, S.; Pieri, K. Assistive technologies for severe and profound hearing loss: Beyond hearing aids and implants. Assist. Technol. 2019, 32, 1-12. [CrossRef]

64. Merat, N.; Jamson, A.H. The effect of stimulus modality on signal detection: Implications for assessing the safety of in-vehicle technology. Hum. Factors 2008, 50, 145-158. [CrossRef]

65. Chourasia, A.; Wiegmann, D.; Chen, K.; Sesto, M. Effect of sitting orientation on touchscreen performance, touch characteristics, user preference, and workload. Iie Trans. Occup. Erg. Hum. Factors 2013, 1, 235-245. [CrossRef]

66. Duff, S.N.; Irwin, C.B.; Skye, J.L.; Sesto, M.E.; Wiegmann, D.A. The effect of disability and approach on touch screen performance during a number entry task. In Proceedings of the Human Factors and Ergonomics Society Annual Meeting, San Francisco, CA, USA, 27 September-1 October 2010; pp. 566-570.

67. Sarcar, S.; Jokinen, J.P.; Oulasvirta, A.; Wang, Z.; Silpasuwanchai, C.; Ren, X. Ability-based optimization of touchscreen interactions. IEEE Pervasive Comput. 2018, 17, 15-26. [CrossRef]

68. Sollerman, C.; Ejeskär, A. Sollerman hand function test: A standardised method and its use in tetraplegic patients. Scand. J. Plast. Reconstr. Surg. Hand Surg. 1995, 29, 167-176. [CrossRef] [PubMed]

69. Zafrulla, Z.; Etherton, J.; Starner, T. TTY phone: Direct, equal emergency access for the deaf. In Proceedings of the 10th International ACM SIGACCESS Conference on Computers and Accessibility, Galway, Ireland, 22-24 October 2008; pp. 277-278.

70. Drennan, W.R.; Rubinstein, J.T. Music perception in cochlear implant users and its relationship with psychophysical capabilities. J. Rehabil. Res. Dev. 2008, 45, 779. [CrossRef]

71. Khing, P.P. Gain Optimization for Cochlear Implant. Systems; The University of New South Wales: Kensington, Australia, 2013.

72. Zhou, Y.; Sim, K.C.; Tan, P.; Wang, Y. MOGAT: Mobile games with auditory training for children with cochlear implants. In Proceedings of the 20th ACM International Conference on Multimedia, Nara, Japan, 29 October-2 November 2012; pp. 429-438.

73. Granquist, C.; Wu, Y.-H.; Gage, R.; Crossland, M.D.; Legge, G.E. How people with low vision achieve magnification in digital reading. Optom. Vis. Sci. Off. Publ. Am. Acad. Optom. 2018, 95, 711. [CrossRef] [PubMed]

74. Broberg, O.; Andersen, V.; Seim, R. Participatory ergonomics in design processes: The role of boundary objects. Appl. Ergon. 2011, 42, 464-472. [CrossRef]

75. Root-Bernstein, R. Problem generation and innovation. Int. Handb. Innov. 2003, 1, 170-179.

76. ISO 20282-1. Ease of Operation of Everyday Products_Part 1: Design Requirements for Context of Use and User Characteristics; International Organization for Standardization: Geneva, Switzerland, 2006.

77. Kleinke, D. Experiential Education and Broad Value Creation is Enabled by the Disabled. In Proceedings of the 2009 ASEE North Central Conference, Columbus, OH, USA, 6 April 2013.

78. Hannukainen, P. Disabled Persons as Lead Users in Mobile User Interface Design. Master's Thesis, University of Detroit, Mercy, Detroit, MI, USA, 2005.

79. Conradie, P.; De Couvreur, L.; Saldien, J.; De Marez, L. Disabled Users as Lead Users in Product Innovation: A Literature Overview. DS 81. In Proceedings of the NordDesign 2014, Espoo, Finland, 27-29 August 2014.

80. Pruitt, J.; Grudin, J. Personas: Practice and theory. In Proceedings of the 2003 Conference on Designing for User Experiences, San Francisco, CA, USA, 6-7 June 2013; pp. 1-15. 